\title{
Loss of polycystins suppresses deciliation via the activation of the centrosomal integrity pathway
}

\author{
Vasileios Gerakopoulos, Peter Ngo, Leonidas Tsiokas (D)
}

\begin{abstract}
The primary cilium is a microtubule-based, antenna-like organelle housing several signaling pathways. It follows a cyclic pattern of assembly and deciliation (disassembly and/or shedding), as cells exit and re-enter the cell cycle, respectively. In general, primary cilia loss leads to kidney cystogenesis. However, in animal models of autosomal dominant polycystic kidney disease, a major disease caused by mutations in the polycystin genes (Pkd1 or Pkd2), primary cilia ablation or acceleration of deciliation suppresses cystic growth, whereas deceleration of deciliation enhances cystogenesis. Here, we show that deciliation is delayed in the cystic epithelium of a mouse model of postnatal deletion of Pkd1 and in Pkd1- or Pkd2-null cells in culture. Mechanistic experiments show that PKD1 depletion activates the centrosomal integrity/mitotic surveillance pathway involving 53BP1, USP28, and p53 leading to a delay in deciliation. Reduced deciliation rate causes prolonged activation of cilia-based signaling pathways that could promote cystic growth. Our study links polycystins to cilia dynamics, identifies cellular deciliation downstream of the centrosomal integrity pathway, and helps explain pro-cystic effects of primary cilia in autosomal dominant polycystic kidney disease.
\end{abstract}

DOI 10.26508/Isa.202000750 | Received 21 April 2020 | Revised 1 July 2020 | Accepted 3 July 2020 | Published online 10 July 2020

\section{Introduction}

The primary cilium is a solitary, antenna-like organelle present virtually in all cell types of the human body. It consists of the axoneme, a microtubular structure sheathed by a specialized form of the plasma membrane and the basal body, a modified centrosome forming the base of the cilium (Haimo \& Rosenbaum, 1981). Cilium assembly and maintenance are achieved by intraflagellar transport (IFT), mediated by the concerted action of anterograde kinesins (IFT-B complex) and retrograde dynein (IFT-A complex) (Ishikawa \& Marshall, 2011; Kobayashi \& Dynlacht, 2011; Nigg \& Stearns, 2011; Sung \& Leroux, 2013). Cilia reach their maximum length in quiescence (G0) and gradually disassemble or shed upon cell cycle reentry (Pugacheva et al, 2007; Liu et al, 2018; Mirvis et al,
2018, 2019; Wang \& Dynlacht, 2018). Gradual ciliary disassembly and shedding is a complex process and although it has been linked to cell cycle progression in cultured cells, its biological role in the context of the whole animal has been unclear (Sanchez \& Dynlacht, 2016; Breslow \& Holland, 2019). Accelerated or reduced rates of ciliary disassembly can decrease or increase the time cells spend in G1 and, thus, enhance or slow down cell cycle reentry, respectively (Kim et al, 2011; Li et al, 2011; Phua et al, 2017). There is also emerging evidence connecting cilia and the DNA damage response (Chaki et al, 2012; Johnson \& Collis, 2016; Walz, 2017). Therefore, it is also conceivable that reduced disassembly rates could also trigger activation of the DNA damage response causing cell arrest in G2 and G1 to fully resorb cilia. In this case, failure to timely disassemble cilia could result in aneuploidy and genomic instability that could lead to uncontrolled proliferation. Therefore, changes in the rate of ciliary disassembly and/or shedding could have positive and negative effects on cell cycle progression dependent upon cell context and type and cilia-based signaling.

HEF1/AURKA/HDAC6 (Pugacheva et al, 2007), Nek2/Kif24 (Kim et al, 2015), and Plk1/ Kif2A (Miyamoto et al, 2015) are major pathways of ciliary disassembly that are activated when cells are induced to reenter the cell cycle. In the HEF1/AURKA/HDAC6 pathway, HEF1 is a scaffold protein which when bound to AURKA induces AURKA autophosphorylation and activation (Nikonova et al, 2013). Activated AURKA phosphorylates HEF1 and HDAC6 (Nikonova et al, 2013). Activated HDAC6 leads to ciliary disassembly by de-acetylating $\alpha-$ tubulin, inducing microtubule depolymerization (Pugacheva et al, 2007). This pathway is silent in $\mathrm{G} 1 / \mathrm{GO}$ and does not contribute to control of ciliary length at $\mathrm{G} 1 / \mathrm{G} 0$, but is activated by up-regulation of HEF1 in response to mitogenic signaling (Pugacheva et al, 2007). AURKA and several other centrosomal proteins including NDE1, a negative regulator of ciliogenesis, form a large complex called the ciliary disassembly complex (CDC) (Gabriel et al, 2016). The activity of CDC can be positively or negatively modulated by several factors / pathways. These pathways include $\mathrm{Ca}^{2+}$ signaling (Plotnikova et al, 2010, 2012), non-canonical Wnt5a signaling (Lee et al, 2012), changes in the composition of phospholipids of the ciliary membrane (Bielas et al, 2009; Phua et al, 2017), and others. Tumor suppressors such as Von Hippel-Lindau (pVHL) (Xu et al, 2010) and phosphatase and tensin homolog (PTEN) (Shnitsar et al, 2015) negatively regulate

Department of Cell Biology, University of Oklahoma Health Sciences Center, Oklahoma City, OK, USA 
ciliary disassembly. In summary, ciliary disassembly is largely controlled by three pathways, which can be further influenced by extracellular/environmental and intracellular factors.

ADPKD is characterized by the formation of massive cysts in the kidney and increased cell proliferation (Bhunia et al, 2002; Kim et al, 2004; Zhou, 2009). In cell culture, loss of Pkd1 or Pkd2 seems to accelerate the $\mathrm{G} 1$ to $\mathrm{S}$ transition by impacting on levels of p21 (Bhunia et al, 2002; Kim et al, 2004; Li et al, 2005; Low et al, 2006). Consistently, the number of actively cycling cells in the cystic epithelium is always markedly increased in Pkd1- or Pkd2-null kidneys compared to wild-type kidneys (Zhou, 2009). Despite the increased proliferation of cystic cells, however, there are no gross ciliary abnormalities in animal models of ADPKD or tissues from patients with ADPKD, with the notable exception of longer cilia in a slowly progressing, hypomorphic mouse model of a human pathogenic mutation (Hopp et al, 2012). This observation suggests that highly proliferating cystic cells seem to have lost the ability to maintain coordination of cell cycle progression and ciliary turnover. These data are also consistent with the idea that persistent cilia-based mitogenic signaling may support cell proliferation and cyst expansion in cells lacking Pkd1 or Pkd2. In fact, double-mutant mice lacking one of the polycystin genes and a gene essential for cilia formation, either ift20 or Kif3a, show a much less severe phenotype, in terms of cyst formation and cell proliferation, compared with single mutants (Ma et al, 2013). Consistently, acceleration of cilia disassembly (Nikonova et al, 2018) suppresses cystic growth and improves kidney function, whereas deceleration of ciliary disassembly has the opposite effects in mouse models of ADPKD (Nikonova et al, 2014).

Our studies presented here show that deletion of Pkd1 or Pkd2 in several cell lines and MEFs leads to an inhibition of serum-induced ciliary disassembly and/or shedding and persistent activation of cilia-based signaling. Delayed disassembly is also seen in a postnatal mouse model of ADPKD. Delayed disassembly induced by the loss of Pkd1 is secondary to the activation of the centrosomal integrity/mitotic surveillance (CI/MS) pathway involving the 53BP1USP28-p53 axis.

\section{Results}

\section{Deletion of $P k d 1 / 2$ induces delayed cilia disassembly}

We generated and characterized a mouse model of ADPKD using the tamoxifen-inducible Ubc-Cre $e^{E R T 2}$ driver to postnatally delete the Pkd1 gene globally (Figs 1A and S1A and B). As reported previously (Piontek et al, 2007; Ma et al, 2013), cell proliferation was markedly increased in cystic kidneys and the number of EdU-positive kidney epithelial cells was higher in 21-d-old Ubc-Cre ${ }^{E R T 2} ; P k d f^{f / f}$ mice induced by 4-hydroxytamoxifen (4-OHT), compared with wild-type littermates. In addition, we noticed that the number of EdU-positive cells with primary cilia was increased by threefold in mutant kidneys compared with wild-type kidneys (Fig 1B and C). To further test whether cystic cells had longer cilia in the $\mathrm{S}$ phase than the wild-type cells, kidney sections were double-labeled for cilia and GEMININ, a protein that accumulates in the S phase (McGarry \& Kirschner, 1998). GEMININ-positive cells with or without cilia were very rare in wild-type kidneys. However, GEMININ-positive cells with cilia were easily identifiable in Pkd1-null kidneys (Fig S1C). These data raised the possibility that disassembly might be compromised or severely delayed in mutant cells.

Ciliary disassembly or shedding is a dynamic process difficult to be recapitulated in vivo. Therefore, we directly tested for an effect of the deletion of $P k d 1$ or $P k d 2$ on serum-induced deciliation in cell culture. Because cilia loss/shortening in response to serum can be mediated by gradual ciliary resorption/disassembly (Pugacheva et al, 2007), instant severing, and/or shedding (Mirvis et al, 2019), we scored cell cultures based on the presence or absence of detectable cilia to account for all modes of cilia loss. From here on, we adapt the term "deciliation" to include all forms of cilia loss. We used three different cell types: MEFs, NIH3T3 fibroblasts, and mouse renal epithelial cells (mIMCD3). Deletion of Pkd1 or Pkd2, achieved either by homologous recombination in MEFs or CRISPR/Cas9 gene editing in NIH3T3 (Fig S2A and B) and MIMCD3 (Kleene \& Kleene, 2016), did not affect the percentage of ciliated cells or ciliary length after $48 \mathrm{~h}$ of serum starvation (Fig S2C), suggesting a lack of an effect of the deletion of Pkd1 or Pkd2 on ciliary assembly. However, deletion of Pkd1 or Pkd2 significantly reduced serum-induced deciliation rates in all cell types, despite different kinetics among these cell types (Figs 2A-D and S2D-G).

To test whether these effects on deciliation were specific to PKD1 or PKD2 and not due to "off-target" effects of CRISPR/Cas9, we transfected back wild-type or mutant forms of PKD1 or PKD2. Adding-back human PKD1 or PKD2 corrected delayed deciliation, indicating a specific effect of PKD1 or PKD2 on deciliation. In contrast, transfection with PKD1 ${ }^{5991}$, a pathogenic mutant of PKD1 that fails to traffic properly to the plasma membrane (Kim et al, 2016), PKD2 ${ }^{\text {D511V }}$, a pathogenic mutant of PKD2 (Reynolds et al, 1999; Koulen et al, 2002) or PKD2 ${ }^{\text {Y684del }}$, which both show reduced channel activity (Zheng et al, 2018), failed to rescue delayed serum-induced deciliation (Fig $2 \mathrm{E}-\mathrm{H}$ ). These results suggested that the observed delay in cilia disassembly was specific to the absence of either polycystin and was reverted by adding back wild-type proteins. Furthermore, they supported the hypothesis that a fully functional PKD1/PKD2 complex, in terms of correct targeting to the plasma membrane and uncompromised channel activity, is essential for proper deciliation.

\section{p53 and TGF $\beta$ /Smad pathways are hyperactivated in Pkd1- and Pkd2-null cells}

To obtain mechanistic insights of delayed deciliation and to also identify hyperactivated signaling pathways in Pkd1- or Pkd2-null cells, we screened a platform of 45 signaling pathways (Cignal Reporter Assays; QIAGEN) for their modulation by the inactivation of Pkd1 or Pkd2. Although kinetics of cystic growth can be different in Pkd1 versus Pkd2 mutant kidneys, we focused on pathways that showed a similar direction of change in pathway activity in Pkd1and Pkd2-null cells compared with wild type, despite different levels. Hyperactivation of p53 and TGF $\beta /$ Smad pathways stood out because they were hyperactivated in 10/10 independent experiments (Fig 3A) in NIH3T3 cells lacking PKD1 or PKD2 and mIMCD3 cells lacking PKD2. Other pathways were also up-regulated in mutant cells (i.e., ATF6, Hedgehog/Gli, E2F1, MYC, and TCF/LEF). 


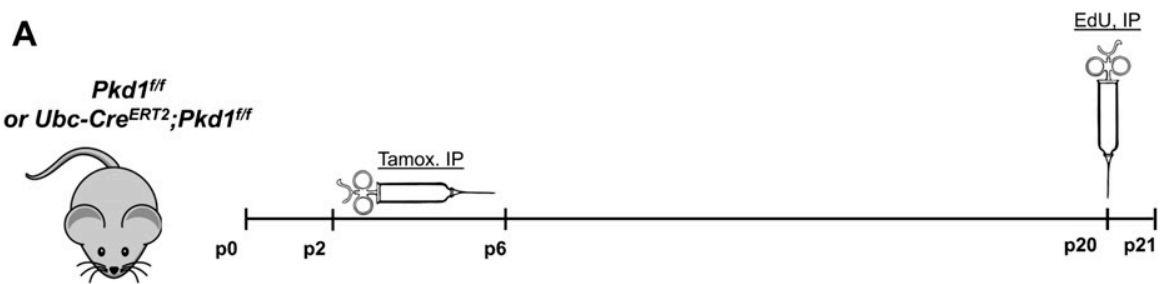

B

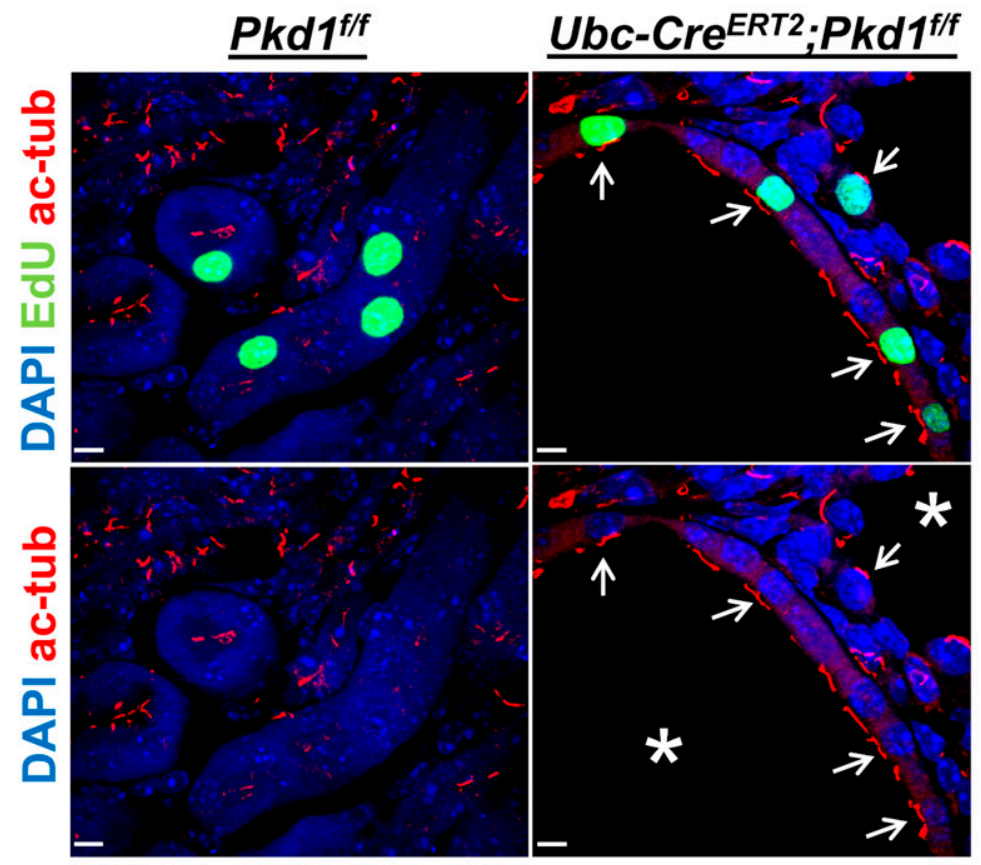

C

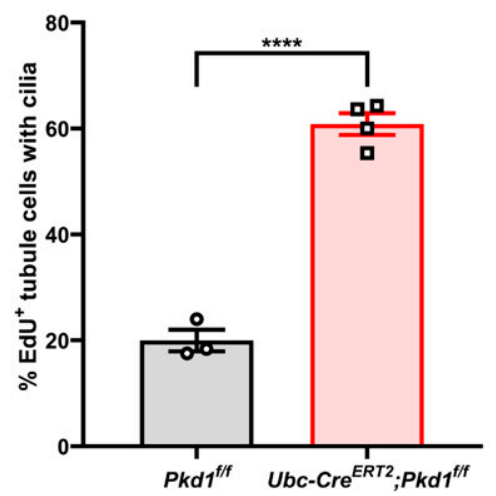

However, pathways such as the MEF2 pathway responded differently to the deletion of $P k d 1$ versus $P k d 2$. Deletion of $P k d 2$ upregulated, whereas deletion of Pkd1 down-regulated MEF2 pathway activity, indicating that deletion of Pkd1 or Pkd2 did not completely overlap in pathway activity. Consistently, kidney-specific knockout of Mef2C reduced cystic growth in Pkd2-null kidneys (Xia et al, 2010). It would be interesting to examine cystic growth in Pkd1/Mef2C compound mice. The TGF $\beta / \mathrm{Smad} 2$ pathway is known to be hyperactivated in kidneys lacking Pkd1 (Hassane et al, 2010; Leonhard et al, 2016) and to induce kidney fibrosis, a prevalent feature of cystic kidneys. It is also known to promote proliferation in NIH3T3 cells
Figure 1. Deletion of Pkd1 increases the number of ciliated $\mathrm{EdU}^{+}$cells in vivo.

(A) Diagram showing administration of 4hydroxytamoxifen (4-OHT) from P2 to P6 and intraperitoneal injection of EdU at P20. (B) Representative images of kidney sections stained for EdU (green) and acetylated $\alpha$-tubulin (cilia, red) of P21 Pkd7 f/f or Ubc-Cre ${ }^{E R T 2} ; P R d 7^{f / f}$ mice induced by 4-OHT from P2 to P6. Arrows indicate EdU ${ }^{+}$cells with cilia. Asterisks indicate cysts. Scale bars: $5 \mu \mathrm{m}$. (C) Percent of $\mathrm{EdU}^{+}$cells with cilia in $P k d f^{f / f}(\mathrm{n}=3)$ and $U$ bc-Cre ${ }^{E R T 2}$; $\operatorname{Pkdf}^{f / f}(\mathrm{n}=4)$ kidneys. 50-100 EdU $\mathrm{Eells}^{+}$per animal were scored for the presence of cilia. Data are presented as means \pm SEM. $t$ test, ${ }^{* \star * *} P<0.0001$.
(Benzakour et al, 1992). Most relevant here, it requires an intact cilium for maximal activity (Clement et al, 2013). Therefore, we examined whether it showed prolonged activity in response to serum in Pkd1-null NIH3T3 cells compared with wild-type cells. Levels of activated phospho-Smad2 ( $\mathrm{p}$-Smad2) were determined at several time points during serum-induced ciliary disassembly in wild-type or Pkd1-null NIH3T3 cells previously synchronized in G1/ G0 (Fig 3B and C). After serum starvation, Smad2 was not activated in wild-type or mutant cells indicating the absence of endogenously secreted ligands of the TGF superfamily. At $1 \mathrm{~h}$ after serum readdition, the level of Smad2 activation was similar in both cell 


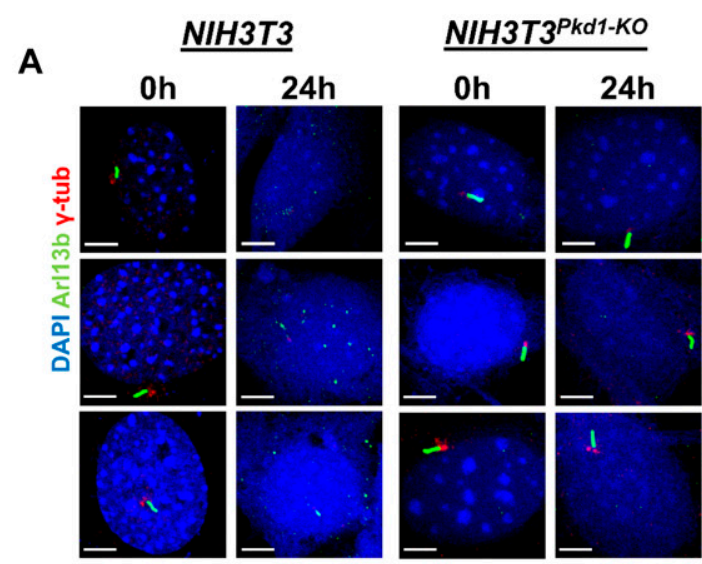

B

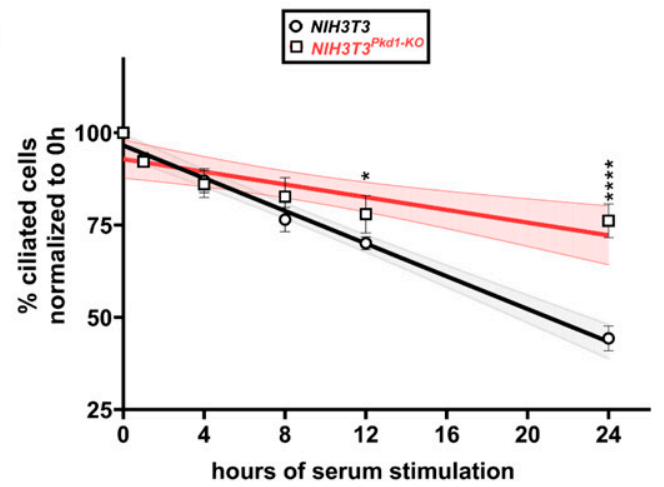

E

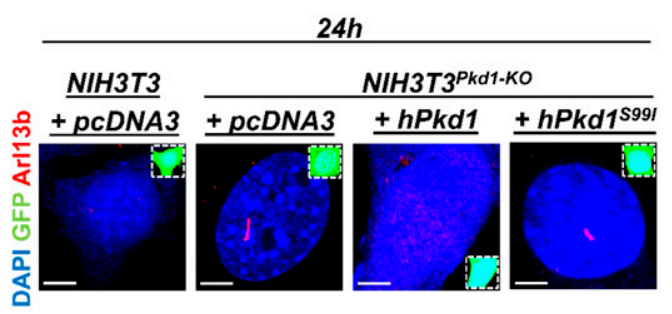

$\mathbf{F}$

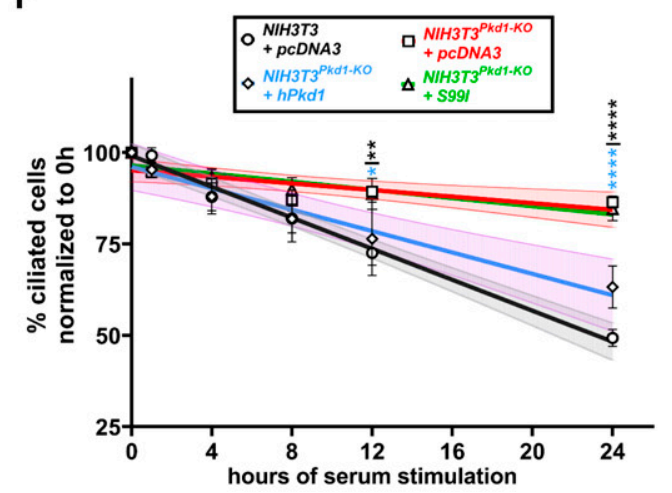

C

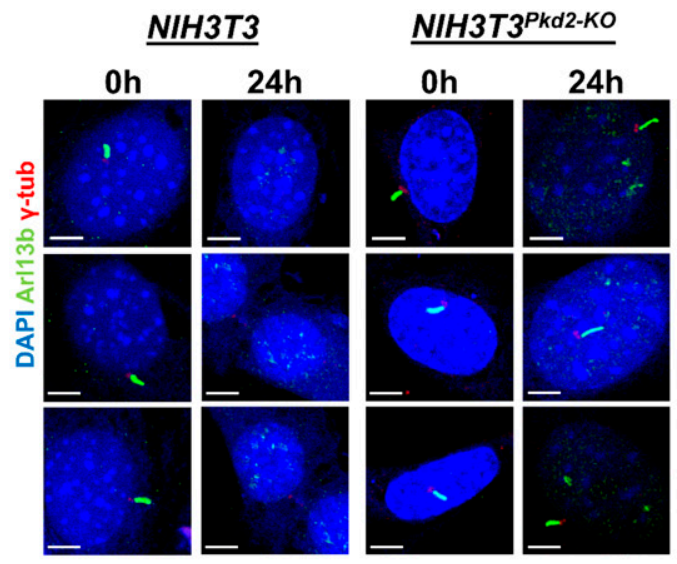

$\mathbf{D}$

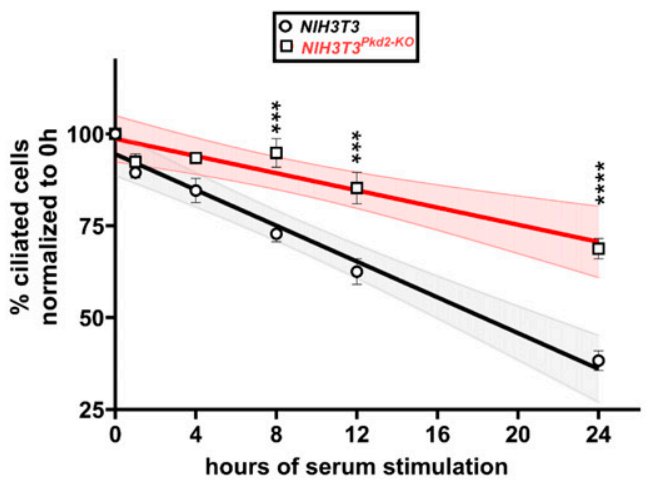

G
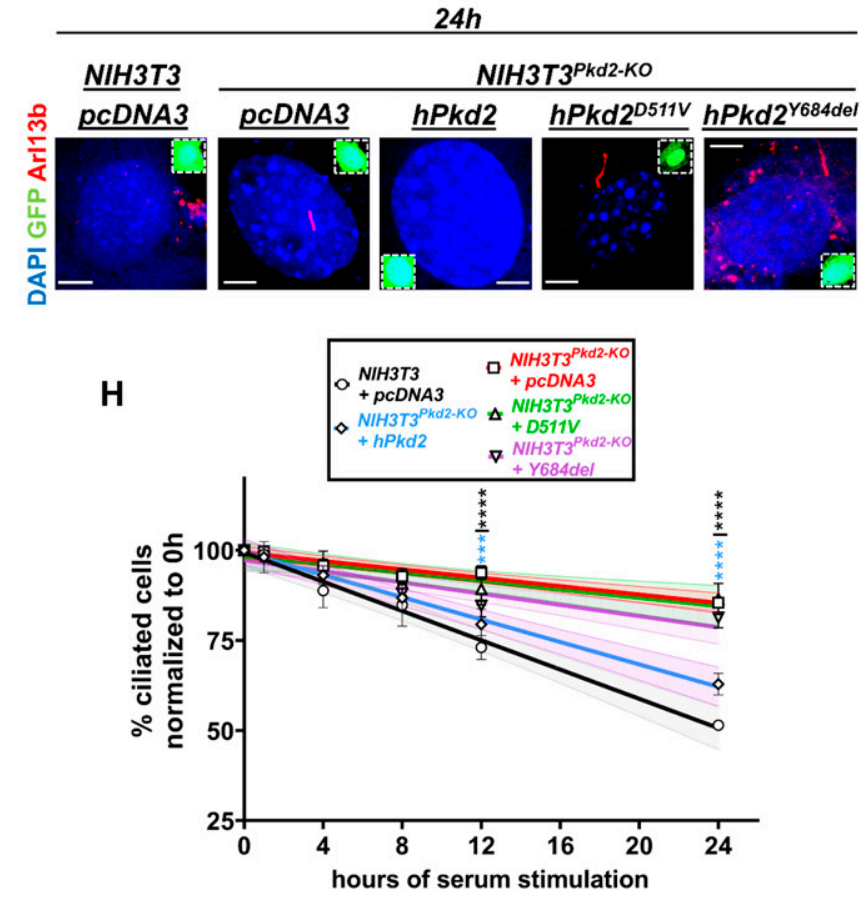

Figure 2. Deletion of Pkd1 or Pkd2 decreases the rate of cell deciliation.

(A, B, C, D) Representative images of wild-type or Pkd1-null NIH3T3 cells (A) and wild-type or Pkd2-null NIH3T3 cells (C) at 0 or $24 \mathrm{~h}$ after serum restimulation, stained for Arl13b (green) and $\gamma$-tubulin (red) to visualize ciliary axoneme and basal body, respectively. Serum-induced deciliation rates shown as best-fits with $95 \%$ confidence limits in indicated cell types $(n=3)(B, D)$. Scale bars: $5 \mu \mathrm{m}$. Data are presented as means \pm SEM. Two-way ANOVA with Holm-Sidak's multiple comparisons test. ${ }^{*} P<0.05,{ }^{* * *} P<$ $0.001,{ }^{* * *} P<0.0001$. (E, F, G, H) Representative images of wild-type, Pkd1-, or Pkd2-null NIH3T3 cells transfected with the indicated constructs and GFP at $24 \mathrm{~h}$ after serum re-addition (E, G). GFP ${ }^{+}$cells (green, insets) were evaluated for the presence or primary cilia via Arl13b (red) staining. Serum-induced deciliation rates shown as 


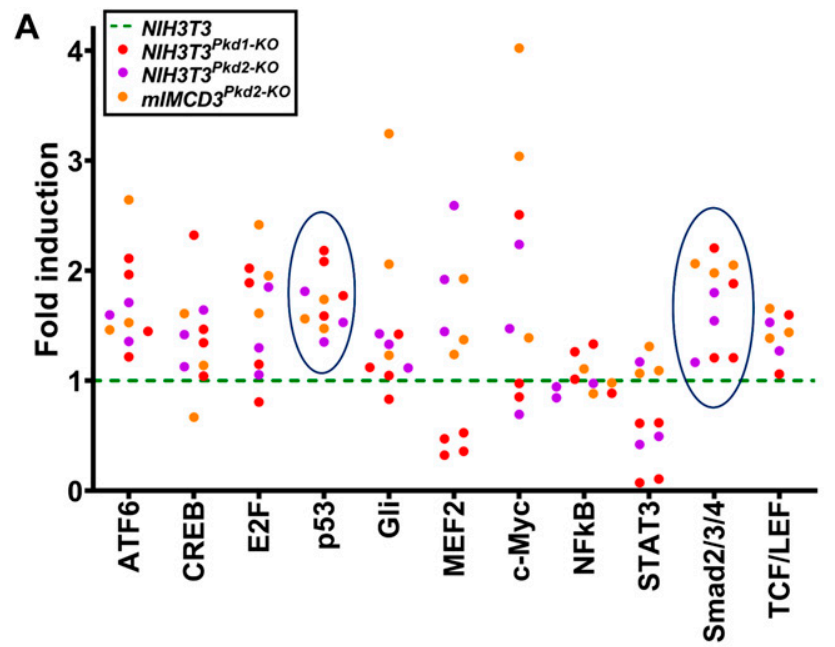

B

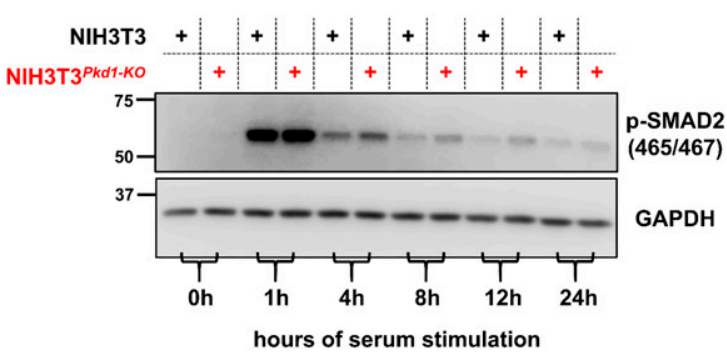

C

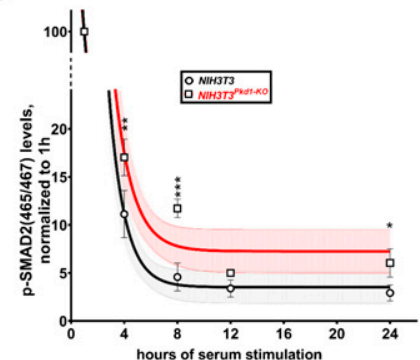

Figure 3. Elevated $\mathrm{p} 53$ and $\mathrm{TGF} \beta / \mathrm{Smad}$ signaling in Pkd1-null NIH3T3 cells.

(A) Summary data of a functional screen for signaling pathways modulated by Pkd1 or Pkd2 inactivation. Foldinduction over wild-type cells (shown by green dotted line) of the indicated signaling pathways in NIH3T3 ${ }^{\text {Pkd1-KO }}(\mathrm{n}=4)$, NIH3T3 ${ }^{\text {PRd2-KO }}(\mathrm{n}=3)$, or mIMCD $3^{P k d 2-K O}(\mathrm{n}=3)$. TGF $\beta /$ Smad and $\mathrm{p} 53$ pathways (circled) were consistently induced in all 10 independent experiments. (B) Representative timecourse of Smad2 activation (phospho-SMAD2 at 465 and 467 ) in response to serum re-addition in wild-type and Pkd1-null NIH3T3 cells. (C) Summary data of (B), shown as best-fits with $95 \%$ confidence limits in indicated cell types $(n=3)$. Data are presented as means \pm SEM. Two-way ANOVA with Holm-Sidak's multiple comparisons test. ${ }^{*} P<0.05,{ }^{* *} P<0.01$, ${ }^{* *} P<$ 0.001 .

Source data are available for this figure. types. However, at all subsequent time points, p-Smad2 levels were higher in mutant cells, suggesting persistent activation of Smad2 during disassembly. These data are consistent with reduced deciliation rates of Pkd1-null cells.

\section{Inhibition of p53 rescues delayed deciliation in Pkd1- or Pkd2-null NIH3T3 cells}

Signaling pathway analysis identified p53 as one of the pathways hyperactivated in Pkd1 or Pkd2 mutant cells. We confirmed that expression levels of p53 were higher in Pkd1- or Pkd2-null cells than those in wild-type cells (Fig 4A). Next, we determined whether p53 levels were also up-regulated in cystic kidneys in 21-d-old Ksp$C r e^{E R T 2} ; P k d 1^{f / f}$ and in 16- or 21-d-old Ubc-Cre ${ }^{E R T 2} ; P k d 1^{f / f}$ mice. We first characterized the Ksp-Cre ${ }^{E R T 2} ; P k d 1^{f / f}$ mouse model (Fig S3A and $B)$. Whereas Ubc-Cre drives the expression of the Cre recombinase in all cell types, the Ksp-Cre ${ }^{E R T 2}$ uses the $C d h 16$ promoter which is active in the epithelial cells of developing nephrons, the ureteric bud, and mesonephric tubules with low recombination efficiency in the proximal tubules (Shao et al, 2002). In the adult kidney, this promoter is active in the collecting ducts, loops of Henle and distal tubules, and to proximal tubules (Shao et al, 2002; Shibazaki et al, 2008). This driver is tamoxifen (4-OHT) inducible. In support of our data in cell culture, protein expression levels of p53 in lysates of P21 cystic kidneys of Ksp-Cre ${ }^{E R T 2} ; P_{k d 1} f^{f / f}$ and P16 or P21 Ubc-Cre ${ }^{E R T 2}$; $\mathrm{Pkdf}^{\mathrm{f} / \mathrm{f}}$ mice, induced by $4-\mathrm{OHT}$ from P2-P6, were increased in mutant kidneys (Figs 4B-D and S3C-E), suggesting that deletion of Pkd1 either ubiquitously or specifically in kidney epithelial cells results in massive activation of p53 in cystic kidneys.

Because PKD1 and PKD2 are present in primary cilia (Yoder et al, 2002; Pazour et al, 2002b) and cyst formation and growth induced by the deletion of Pkd1 or Pkd2 share several characteristics of cystogenesis in cilia mutants (Davenport et al, 2007; Piontek et al, 2007), we reasoned that loss of $P k d 1$ or $P k d 2$ may have resulted in some sort of a structural defect of cilia and/or centrosome/basal body that could be sensed by the centrosomal integrity/mitotic surveillance pathway leading to the activation of p53. This pathway is activated by centrosomal loss and not by centrosomal amplification or DNA damage (Fong et al, 2016; Lambrus et al, 2016; Meitinger et al, 2016; Lambrus \& Holland, 2017). Consistent with this hypothesis, we did not see differences in the number of phosphoH2AX ( $y$-H2AX)-positive wild-type and Pkd1-null NIH3T3 cells or wild-type and mutant kidneys staining (Fig S4A and B), indicating that DNA double-stranded breaks and genomic instability is unlikely to account for the delayed disassembly in mutant cells. Core components of the $\mathrm{CI} / \mathrm{MS}$ pathway include 53BP1, USP28, and p53.

best-fits with $95 \%$ confidence limits in indicated cell types $(n=3)(F, H)$. Scale bars: $5 \mu$ m. Data are presented as means \pm SEM. Two-way ANOVA with Holm-Sidak's multiple comparisons test. All comparisons were performed against the control group time points (NIH3T3 ${ }^{P k d 1-K O}$ transfected with pcDNA3 or NIH3T3 ${ }^{P k d 2-K O}$ transfected with pcDNA3, red curves). Color of the asterisks indicates comparison of the respective color group with the control group. ${ }^{\star} P<0.05$, ${ }^{* *} P<0.01,{ }^{\star * *} P<0.001$, ${ }^{\star * * *} P<0.0001$. 
A B

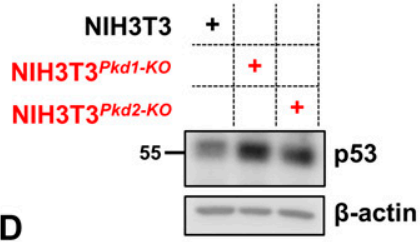

B

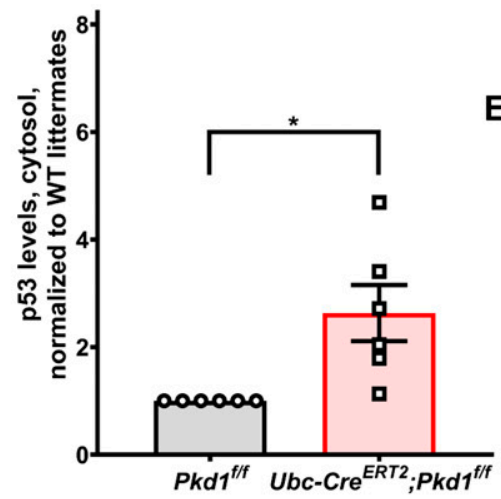

E
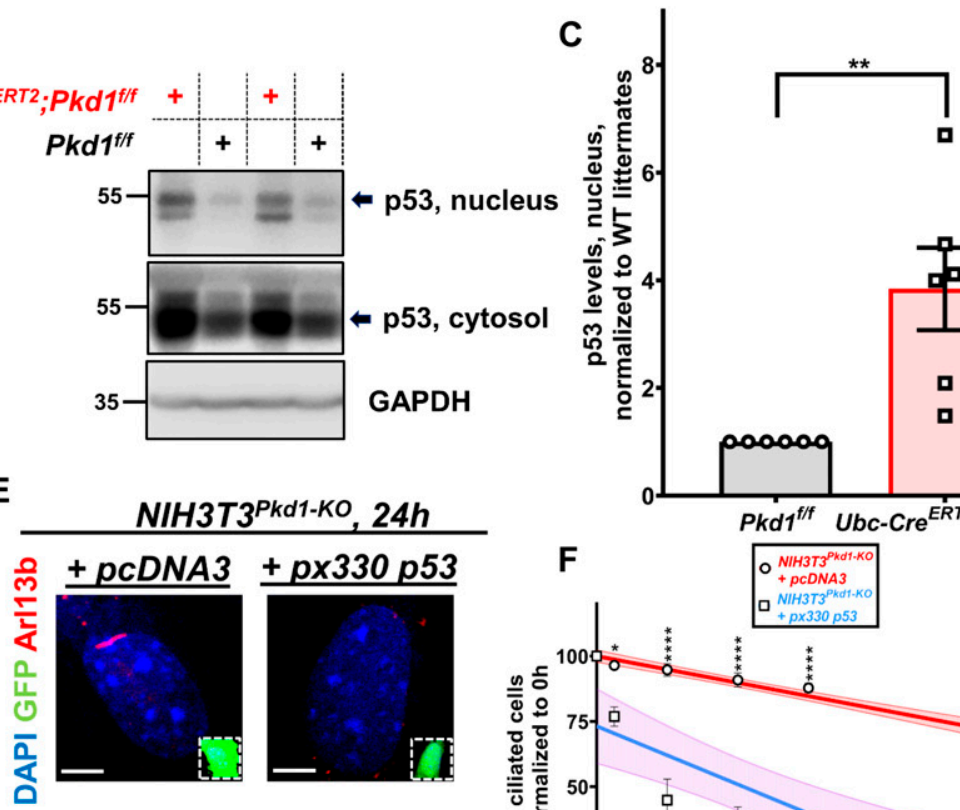

G

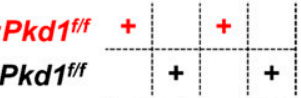
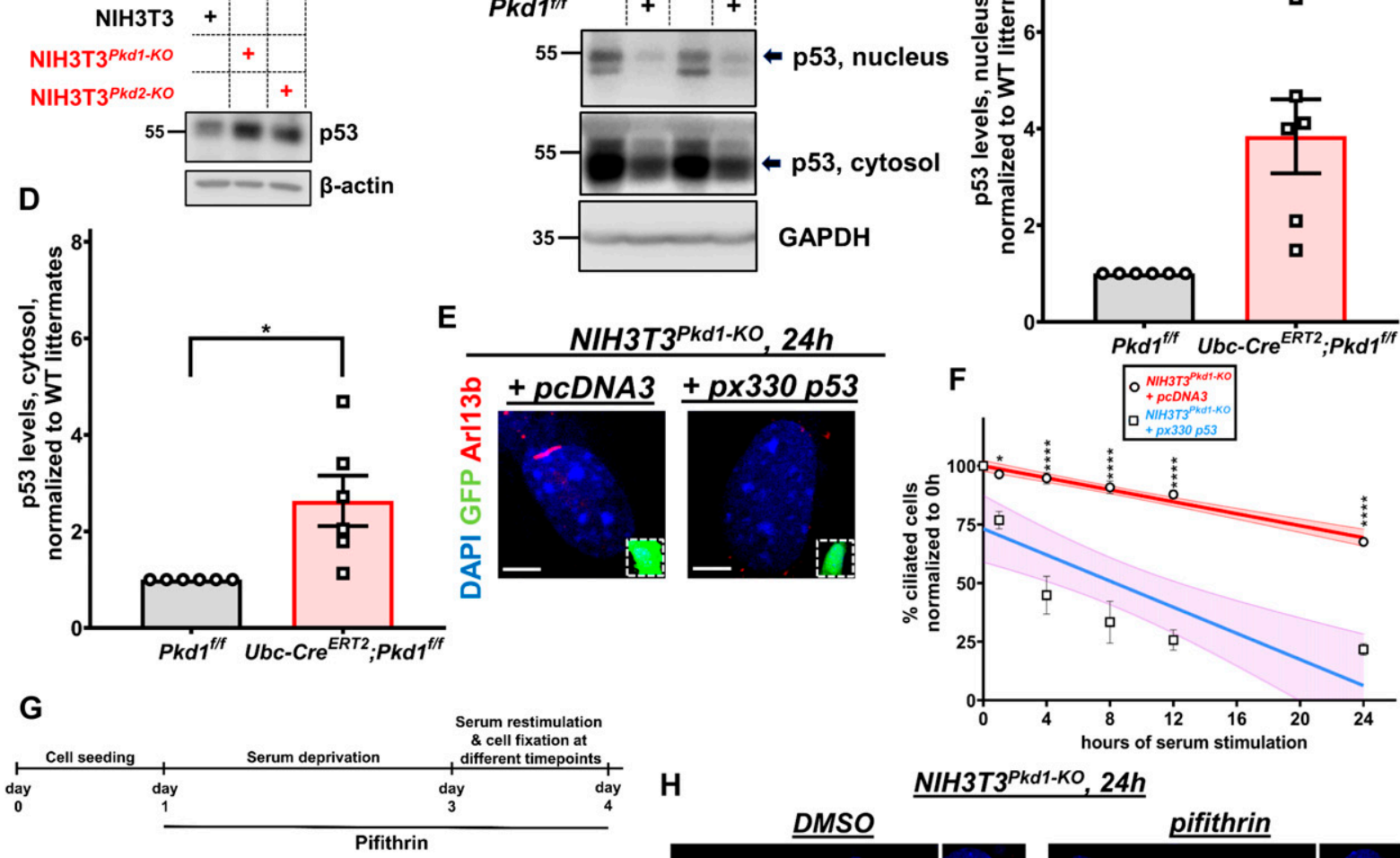

H
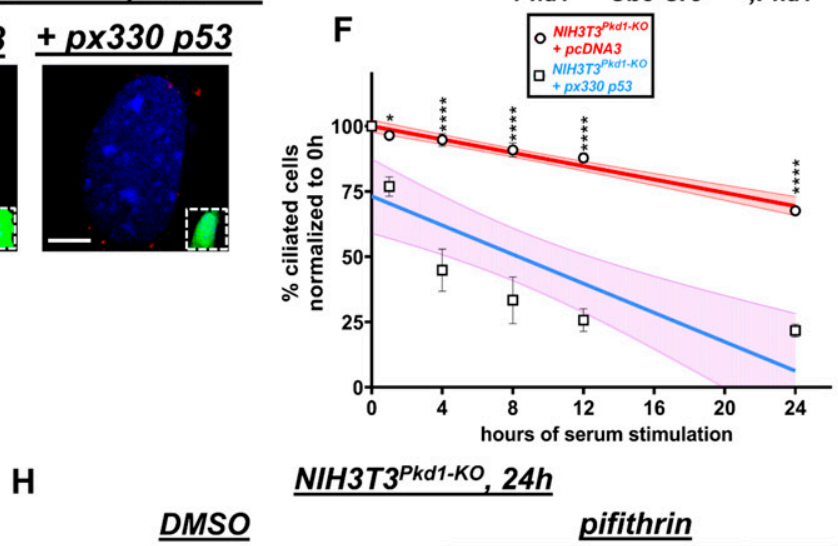

NIH3T3 ${ }^{\text {Pkd1-KO }, 24 h}$
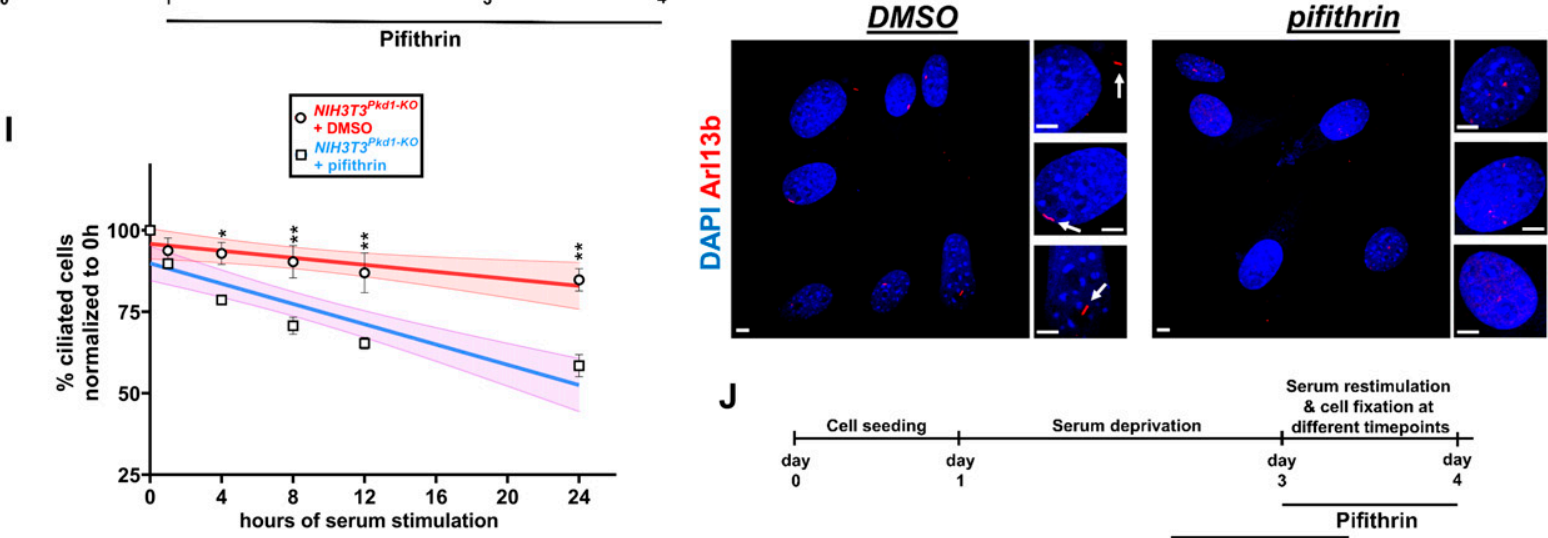

K

NIH3T3 ${ }^{\text {Pkd1-KO }}$, 24h
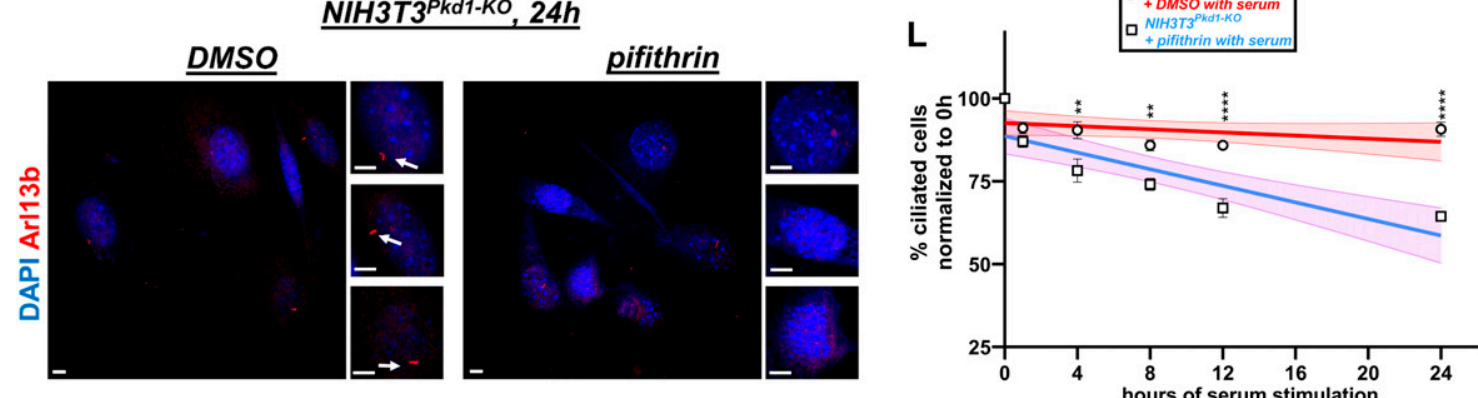

Figure 4. Serum-induced deciliation is dependent on p53 in Pkd1-null NIH3T3 cells.

(A) Expression levels of p53 in total cell lysates of wild-type, Pkd1-null, or Pkd2-null NIH3T3 cells. (B) Expression levels of p53 in nuclear and cytosolic extracts derived from P21 kidneys of Pkd1 f/f and Ubc-Cre ${ }^{E R T 2} ; P k d 7^{f / f}$ mice treated with 4-OHT. (C, D) Quantification of protein levels of p53 in the nucleus (C) and cytosol (D), normalized to wild-type littermates pooled from three pairs of P16 and three pairs of P21 littermates. Data are presented as means \pm SEM. $t$ test. ${ }^{*} P<0.05,{ }^{* \star} P<0.01$. (E, F) Representative images from Pkd1-null NIH3T3 cells (E) co-transfected with the indicated constructs and GFP at $24 \mathrm{~h}$ after serum re-addition. pcDNA3 was used as negative control. px330 p53 expresses a p53-specific single guide RNA. GFP ${ }^{+}$cells (green, insets) were evaluated for the presence or primary cilia via Arl13b (red) staining. Serum-induced 
Inactivation of the $p 53$ gene via CRISPR/Cas9 gene editing (Figs 4E and $\mathrm{F}$ and $\mathrm{S} 5 \mathrm{~A}$ and $\mathrm{B}$ ) or inhibition of its transcriptional activity by pifithrin (Figs 4G-I and S5C and D) restored delayed deciliation in Pkd1- or Pkd2-null NIH3T3 cells. Addition of pifithrin immediately after serum re-addition had similar effects in Pkd1- or Pkd2-null cells (Figs $4 J-L$ and S5E and F), indicating an acute effect of p53 on deciliation within $\mathrm{G} 1$ and/or S phases of the same cycle. Deletion or inhibition of p53 had no effect on wild-type cells (Fig S5G-I). Thus, these data showed that deletion of Pkd1 or Pkd2 in cultured cells or kidneys leads to an increase in p53 levels and activity that is responsible for the inhibition of serum-induced cell deciliation.

Next, we tested whether depletion of 53BP1 and USP28 would have similar effects to the deletion of p53 on deciliation in Pkd1null cells. Although not statistically significant, mRNA levels of both 53bp1 and Usp28 were elevated in serum-starved Pkd1-null cells compared with wild-type cells (Fig 5A and B). This trend of increased mRNA levels of Usp28 and 53bp1 at baseline ( $0 \mathrm{~h}$ ) could be suggestive of activation of the $\mathrm{Cl} / \mathrm{MS}$ before serum re-addition. Downregulation of both of these proteins (Fig S6A-D) restored deciliation in mutant cells (Fig 5 C and D). Overall, these data suggested that deletion of $P k d 1$ or $P k d 2$ led to the activation of the $\mathrm{Cl} / \mathrm{MS}$ pathway, which in turn led to the activation of p53 activity to suppress deciliation. The elevated 53bp1 and Usp28 mRNA levels in G1/G0 suggest that a centrosomal "defect" might have been induced earlier, but it did not manifest until cells were induced to deciliate. We speculated that overexpression of core components of the $\mathrm{Cl} /$ MS pathway in wild-type NIH3T3 cells should be able to recapitulate the delay in deciliation observed in Pkd1-null cells. Indeed, overexpression of USP28, 53BP1, both USP28 and 53BP1, or p53 was able to suppress deciliation in wild-type cells (Fig 5E and F). Overall, these results support the conclusion that activation of the $\mathrm{CI} / \mathrm{MS}$ pathway inhibits deciliation and not the opposite.

\section{Pkd1-null cells show decreased levels of NDE1 during serum- induced deciliation}

To understand how increased p53 activity could inhibit deciliation, we examined expression levels of known disassembly factors or negative regulators of cilia formation. NDE1 is a negative regulator of ciliogenesis, whose expression is induced upon cell cycle reentry but suppressed in G1/G0 via SCF ${ }^{\text {FBW7 }}$ E3 ligase (Maskey et al, 2015). Pkd1-null cells showed reduced levels of NDE1 upon serum readdition, compared with wild-type cells (Fig 6A and B). To further test the possible role of p53 in the reduction of NDE1 protein expression levels during deciliation, we treated wild-type NIH3T3 cells with nutlin, a stabilizer of p53, immediately after serum restimulation, and determined NDE1 protein levels at $24 \mathrm{~h}$ and the percentage of ciliated cells at 8 and $24 \mathrm{~h}$ after serum re-addition. Nutlin treatment compromised NDE1 protein levels and cell deciliation in wild-type NIH3T3 cells (Fig 6C-E). These data suggested that increased p53 activity can suppress NDE1 protein levels. However, because deciliation was suppressed at concentrations of nutlin that were ineffective in suppressing NDE1 levels $(20 \mu \mathrm{M})$, we suggest that other p53-regulated proteins can be affected in parallel with NDE1 to suppress deciliation in these cells.

We reasoned that adding back NDE1 in Pkd1-null cells should promote deciliation, if low NDE1 levels had a causal role in reduced deciliation rate observed in these cells. However, overexpression of NDE1 throughout the cell cycle has a robust effect in suppressing ciliation. To maximize the expression of NDE1 in the G1/S phase (when deciliation occurs), we used a tetracycline-inducible vector to induce expression of NDE1 at the time of serum re-addition. We also fused at its $C$ terminus amino acid residues 1-110 of human GEMININ containing a well-established APC/C phosphodegron (McGarry \& Kirschner, 1998), to ensure almost complete degradation at G0 (Fig 6F). As shown in Fig 6G-I, the percentage of ciliated cells, at 12 and $24 \mathrm{~h}$ after serum re-addition, in Pkd1-null NIH3T3 cells transfected with NDE1-hGEM and induced by $2 \mu \mathrm{g} / \mathrm{ml}$ doxycycline at the 0 -h time point, was reduced to wild-type levels. Overexpression of this construct and induction of expression by similar concentration of doxycycline did not accelerate disassembly in wild-type cells. We reasoned that because ciliation levels in mock-transfected and NDE1-hGEM-transfected Pkd1-null cells are similar at $0 \mathrm{~h}$ of serum re-addition, but deciliation is enhanced after serum re-addition in NDE1-hGEM-transfected mutant cells, NDE1 could function as a serum-induced deciliation factor, and its observed down-regulation in Pkd1-null cells could have a causal effect in the suppressed rate of deciliation in these cells. Overall, these data suggest that NDE1 could function downstream of PKD1 in serum-induced deciliation in NIH3T3 cells.

\section{Discussion}

Although it was realized $18 \mathrm{yr}$ ago that cilia can have a major role in the pathogenesis of polycystic kidney disease (Pazour \& Rosenbaum, 2002; Pazour et al, 2002a), the exact cellular mechanism of how cilia contribute to cyst formation/progression in ADPKD still remains unknown. Because cilia appear of normal size in several mouse models of ADPKD, it is thought that loss of polycystins may have a primary role in modulating ciliary function rather than structure (Nauli et al, 2003; Pazour, 2004; Ma et al, 2013). Our studies challenge this idea, by showing that altered ciliary function is secondary to defective deciliation. This is consistent

deciliation rates are shown as best-fits with $95 \%$ confidence limits in indicated cell types $(n=3)(F)$. Scale bars: $5 \mu$ m. Data are presented as means \pm SEM. Two-way ANOVA with Holm-Sidak's multiple comparisons test. ${ }^{*} P<0.05,{ }^{* * *} P<0.0001$. (G, $\left.\mathbf{H}, \mathbf{I}\right)$ Diagram showing treatment with $10 \mu \mathrm{M}$ pifithrin during serum starvation and during serum restimulation (G). Representative images of primary cilia (Arl13b, red) from Pkd1-null cells ( $\mathrm{H}$ ) at $24 \mathrm{~h}$ after serum restimulation, after the indicated treatment. Serum-induced deciliation rates are shown as best-fits with $95 \%$ confidence limits in indicated cell types $(n=3)(\mathrm{I})$. Arrows indicate primary cilia. Scale bars: $5 \mu$ m. Data are presented as means \pm SEM. Two-way ANOVA with Holm-Sidak's multiple comparisons test. ${ }^{*} P<0.05$, ${ }^{*} P<0.01$. (J, K, L) Diagram showing treatment with $10 \mu M$ pifithrin only during serum restimulation (J). Representative images of primary cilia (Arl13b, red) from Pkd1-null cells (K) at $24 \mathrm{~h}$ after serum restimulation, after the indicated treatment. Serum-induced deciliation rates are shown as best-fits with $95 \%$ confidence limits in indicated cell types $(n=3)(L)$. Arrows indicate primary cilia. Scale bars: $5 \mu \mathrm{m}$. Data are presented as means \pm SEM. Two-way ANOVA with Holm-Sidak's multiple comparisons test. ${ }^{* *} P<0.01,{ }^{* * * *} P<0.0001$.

Source data are available for this figure. 


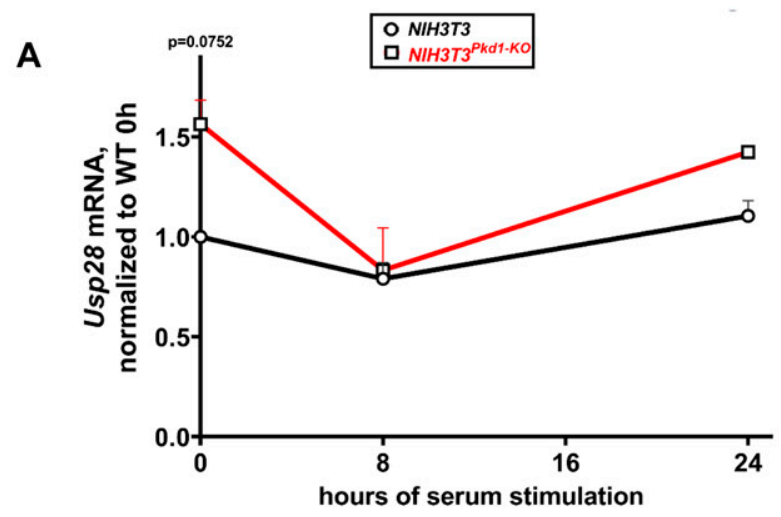

C

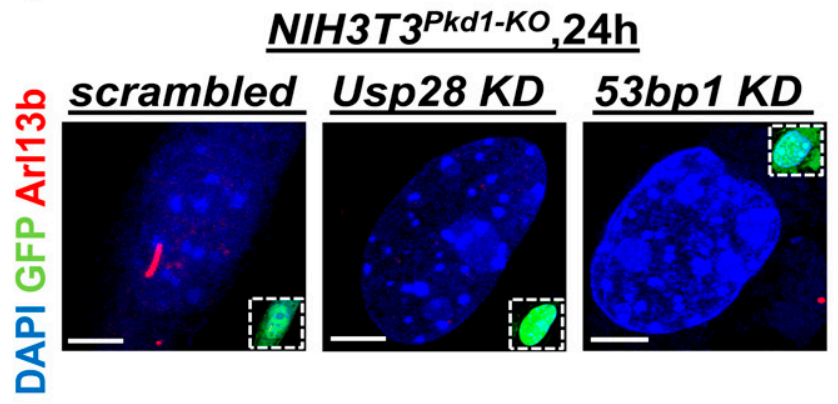

E

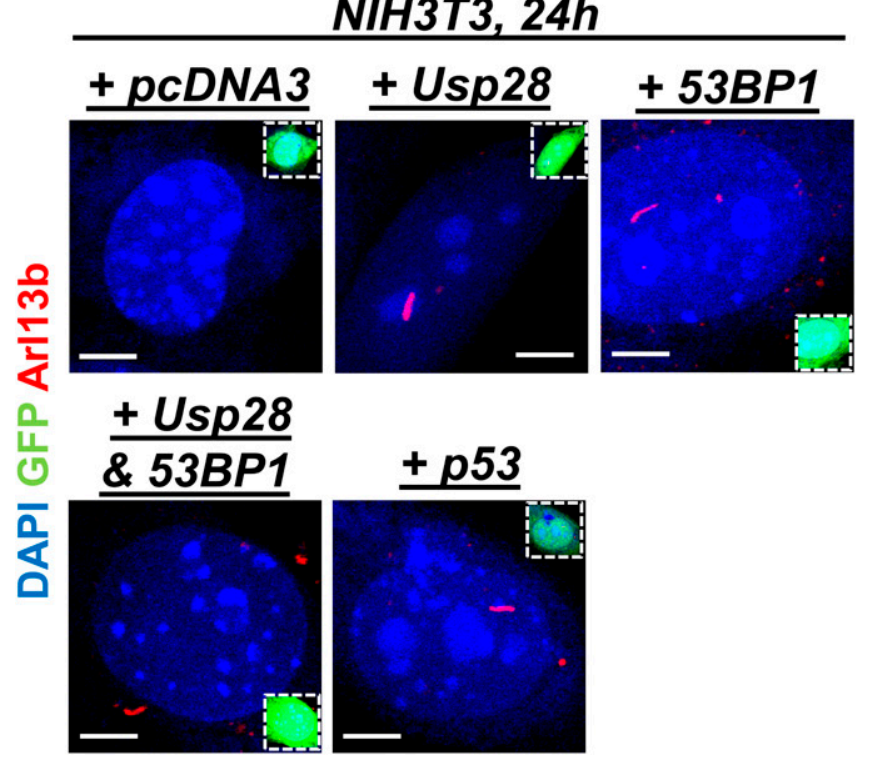

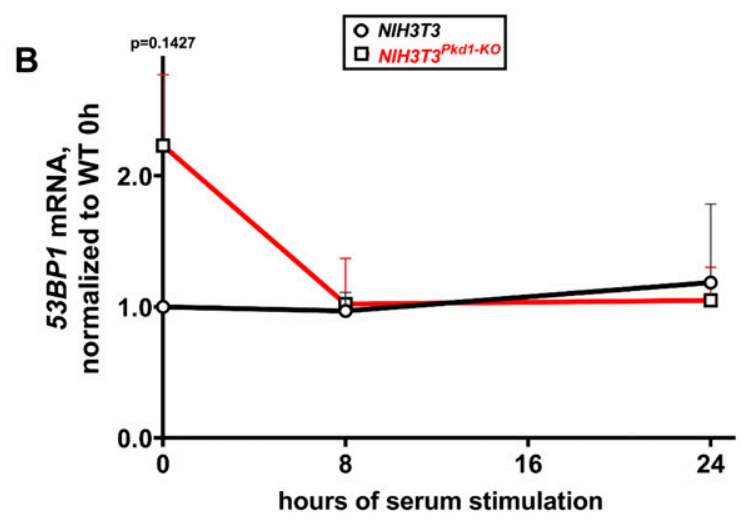

D

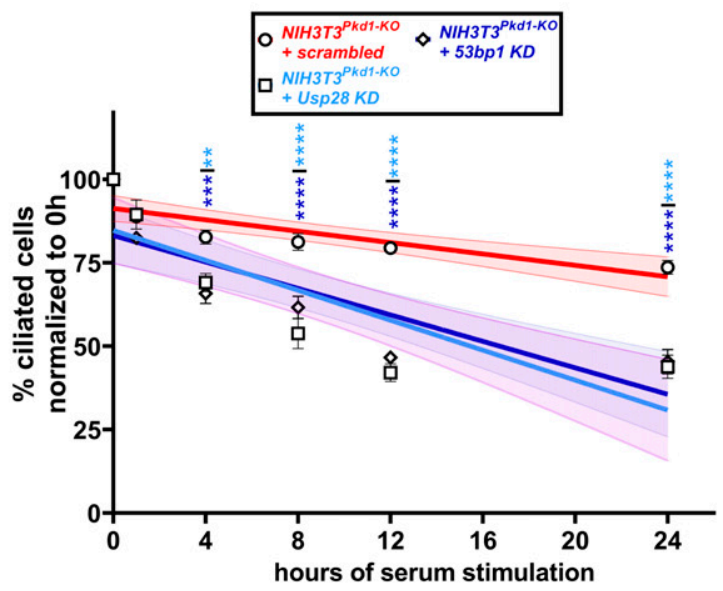

$\mathbf{F}$
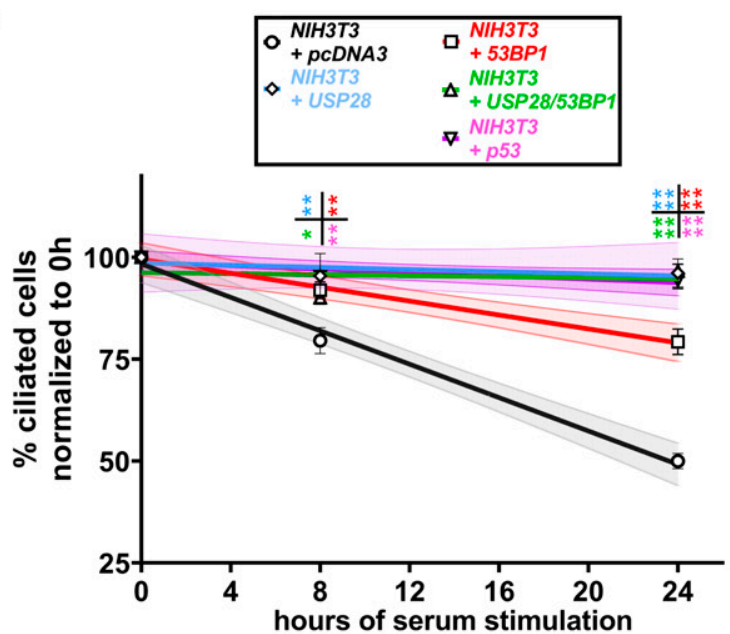

Figure 5. Serum-induced deciliation rate is modulated by components of the centrosomal integrity/mitotic surveillance pathway.

(A, B) Usp28 (A) and 53bp1 (B) mRNA levels in wild-type or Pkd1-null NIH3T3 cells, at various time points after serum re-addition ( $\mathrm{n}=3$ ). Data are presented as means \pm SEM. Two-way ANOVA with Holm-Sidak's multiple comparisons test. (C, D) Representative images from Pkd1-null cells transfected with the indicated constructs and GFP at $24 \mathrm{~h}$ after serum re-addition (C). GFP ${ }^{+}$cells (green, insets) were evaluated for the presence or primary cilia via Arl13b (red) staining (C). Serum-induced deciliation rates are shown as best-fits with $95 \%$ confidence limits in indicated cell types $(n=3)(D)$. Scale bars: $5 \mu$ m. Data are presented as means \pm SEM. Two-way ANOVA with Holm-Sidak's multiple comparisons test. All comparisons were performed against the control group time points (NIH3T3 ${ }^{\text {PRd1-KO }}$ transfected with scrambled siRNA, red 
with previous data showing that primary cilia ablation (Ma et al, 2013) or acceleration of cilia disassembly suppresses cystic growth (Nikonova et al, 2018), whereas deceleration of ciliary disassembly enhances cystic growth in mouse models of ADPKD (Nikonova et al, 2014). Our data point to serum-induced deciliation as a cellular process impacted by the loss of polycystins.

We suggest that the $\mathrm{Cl} / \mathrm{MS}$ pathway is a critical intermediary between the loss of polycystins and reduced rate of serum-induced deciliation. This conclusion is based on the following lines of evidence. First, cells lacking Pkd1 or Pkd2 do not show differences in ciliation levels or ciliary length upon serum starvation, indicating that loss of PKD1 or PKD2 does not impact cilia assembly programs. In contrast, cells lacking Pkd1 or Pkd2 show a reduced rate of serum-induced deciliation that is rescued by knocking down or inhibiting components of the Cl/MS pathway such as USP28, 53BP1, and p53. Conversely, overexpression of these factors in wild-type cells induces delayed deciliation, indicating that activation of the $\mathrm{Cl} / \mathrm{MS}$ pathway is downstream of polycystin loss and upstream of delayed disassembly. Second, renal cells lining the cystic epithelium in ADPKD mouse models show not only a higher number of EdU-positive cells but also a higher number of EdU-positive cells with primary cilia than the wild-type cells, suggesting that cell deciliation is compromised, yet entry into $S$ is up-regulated in mutant cells. This suggests a possible uncoupling of the tight coordination of deciliation and cell cycle progression. Third, overexpression of NDE1 during disassembly induces deciliation in mutant cells, but not in wild-type cells. This finding indicates that NDE1 has a negative effect on cilia biogenesis and maintenance, but not on cilia undergoing disassembly or shedding, despite the fact that it was identified as a component of the CDC (Gabriel et al, 2016). An important question is how p53 activation leads to reduced protein levels of NDE1 expression. Because p53 mediates its effects by transcriptional activation, we believe that the effect of p53 on NDE1 is indirect, perhaps via transcriptional induction of factor(s) that down-regulate NDE1 and additional deciliation factors. These lines of evidence lead us to propose a model in which, deletion of polycystins activates the $\mathrm{Cl} / \mathrm{MS}$ pathway by increasing the levels/ activity of USP28, 53BP1, and p53. Activation of this pathway pauses serum-induced deciliation allowing persistent activation of ciliary signaling pathways. These pathways can include the TGF- $\beta / \mathrm{Smad}$, Hedgehog, canonical Wnt/ $\beta$-catenin, and others that could promote cystic growth in a linear and/or parallel ways (Fig 7).

Our data, however, do not support a direct effect of the loss of polycystins on serum-induced deciliation but rather an indirect effect via the activation of the $\mathrm{Cl} / \mathrm{MS}$ pathway. We show that deletion or pharmacologic inhibition of p53, 53BP1, or USP28 restores deciliation rates in cells lacking Pkd1. These data suggest that these proteins function downstream of the loss of Pkd1 in deciliation. We do not know, yet, exactly how loss of Pkd1 or Pkd2 activates the $\mathrm{Cl}$ /
MS pathway. Because this pathway can be activated by centrosomal loss, mitotic delay, or both, in which case centrosomal loss induces mitotic delay (Lambrus \& Holland, 2017), it is possible that one of the normal functions of the polycystins could be to maintain $\mathrm{Cl}$. However, we do not see centrosomal loss, gross centrosomal abnormalities, such as fragmentation, or amplification in Pkd1- or Pkd2-null cells, despite previous reports of centrosomal amplification in Pkd1- or Pkd2-null MEFs and kidneys (Battini et al, 2008; Burtey et al, 2008). It should be noted that even if centrosomal amplification occurs in Pkd1-null NIH3T3 cells above their known levels of $6 \%$ (Wong et al, 2015), the $\mathrm{Cl} /$ MS pathway should not be activated by centrosomal amplification but rather by centrosomal loss. We favor the idea that wild-type polycystins may have an essential role in maintaining $\mathrm{Cl}$, and their loss induces subtle structural changes even before cells are induced to enter the cell cycle, because 53bp1 and Usp28 mRNA levels were elevated in serum-starved cells. Because the centrosome is a membrane-less organelle, it is unlikely that the PKD1/PKD2 complex physically contributes to $\mathrm{Cl}$. However, PKD1/PKD2-mediated $\mathrm{Ca}^{2+}$ signaling could affect critical aspects of centrosome biogenesis, maturation, and maintenance. In support of this hypothesis, mutant forms of PKD1 or PKD2 that compromise channel activity failed to rescue deciliation defects in Pkd1- or Pkd2-mutant cells, indicating that presence of a functional polycystin complex is necessary for $\mathrm{Cl}$ / normal deciliation. More work in the future would be needed to identify the mechanism by which polycystin loss triggers the $\mathrm{Cl} / \mathrm{MS}$ pathway.

Our data show that the percentage of ciliated cells or ciliary length is unchanged in serum-starved cells lacking Pkd1 or Pkd2 and wild-type cells. Therefore, we do not have evidence to believe that loss of polycystins affects cilia assembly programs. This is consistent with our mouse data, in which ciliary length does not seem to be grossly different between wild-type and mutant cells, unless cells are actively cycling as determined by EdU labeling. It can be argued that a 24-h pulse of EdU could mark cells in all phases of the cell cycle, including G1. However, at P21, cell proliferation is extremely low in the kidney, as shown earlier that a 3-h BrdU pulse at P24 labeled only $4 \%$ of cystic cells and $0 \%$ of wild-type cells (Shibazaki et al, 2008). Therefore, the chance of an EdUpositive cell to be in the G1 phase after having gone through the $\mathrm{S}, \mathrm{G} 2$, and $\mathrm{M}$ phases is quite low. Moreover, a cell that has transited from S to G1 within $24 \mathrm{~h}$ should produce two EdU-labeled daughter cells localized next to each other, which we do not see. Therefore, we favor the idea that EdU-positive cells represent cells mostly in the $\mathrm{S}$ phase and to a lesser extent in G2. This is supported by our data identifying GEMININ-positive cells with cilia in mutant kidneys, but not in wild-type kidneys. Based on DAPI staining, we do not see many dividing cells and according to $\mathrm{y}-\mathrm{H} 2 \mathrm{AX}$ staining, we conclude that cells undergoing DNA damage or experiencing genomic

curve). Color of the asterisks indicates comparison of the respective color group with the control group. ${ }^{* *} P<0.01$, ${ }^{* * *} P<0.001$, ${ }^{* * * *} P<0.0001$. (E, $\mathbf{F}$ ) Representative images from wild-type NIH3T3 cells transfected with the indicated constructs and GFP at $24 \mathrm{~h}$ after serum re-addition. GFP ${ }^{+}$cells (green, insets) were evaluated for the presence or primary cilia via Arl13b (red) staining (E). Serum-induced deciliation rates are shown as best-fits with $95 \%$ confidence limits in indicated cell types ( $n=3)(F)$. Scale bars: $5 \mu \mathrm{m}$. All comparisons were performed against the control group time points (NIH3T3 transfected with pcDNA3, black curve). Color of the asterisks indicates comparison of the respective color group with the control group. Data are presented as means \pm SEM. Two-way ANOVA with Holm-Sidak's multiple comparisons test. ${ }^{\star} P<$ $0.05,{ }^{* *} P<0.01,{ }^{* * *} P<0.0001$. 


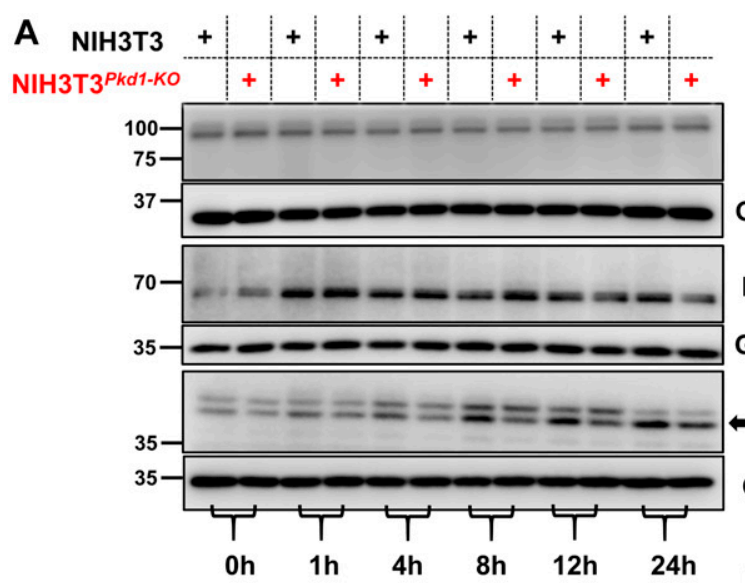

B

C

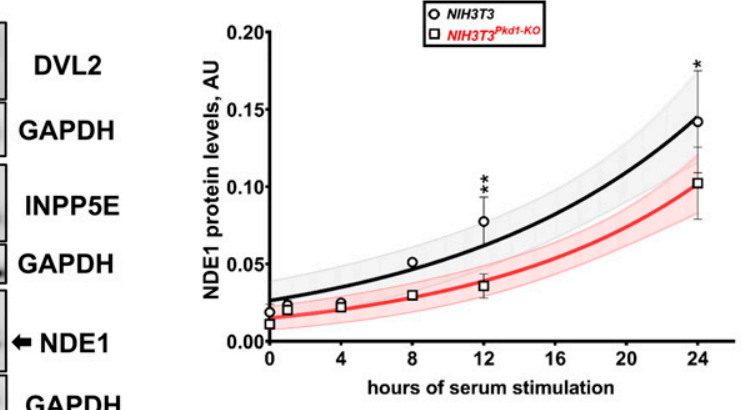

NIH3T3, 24h
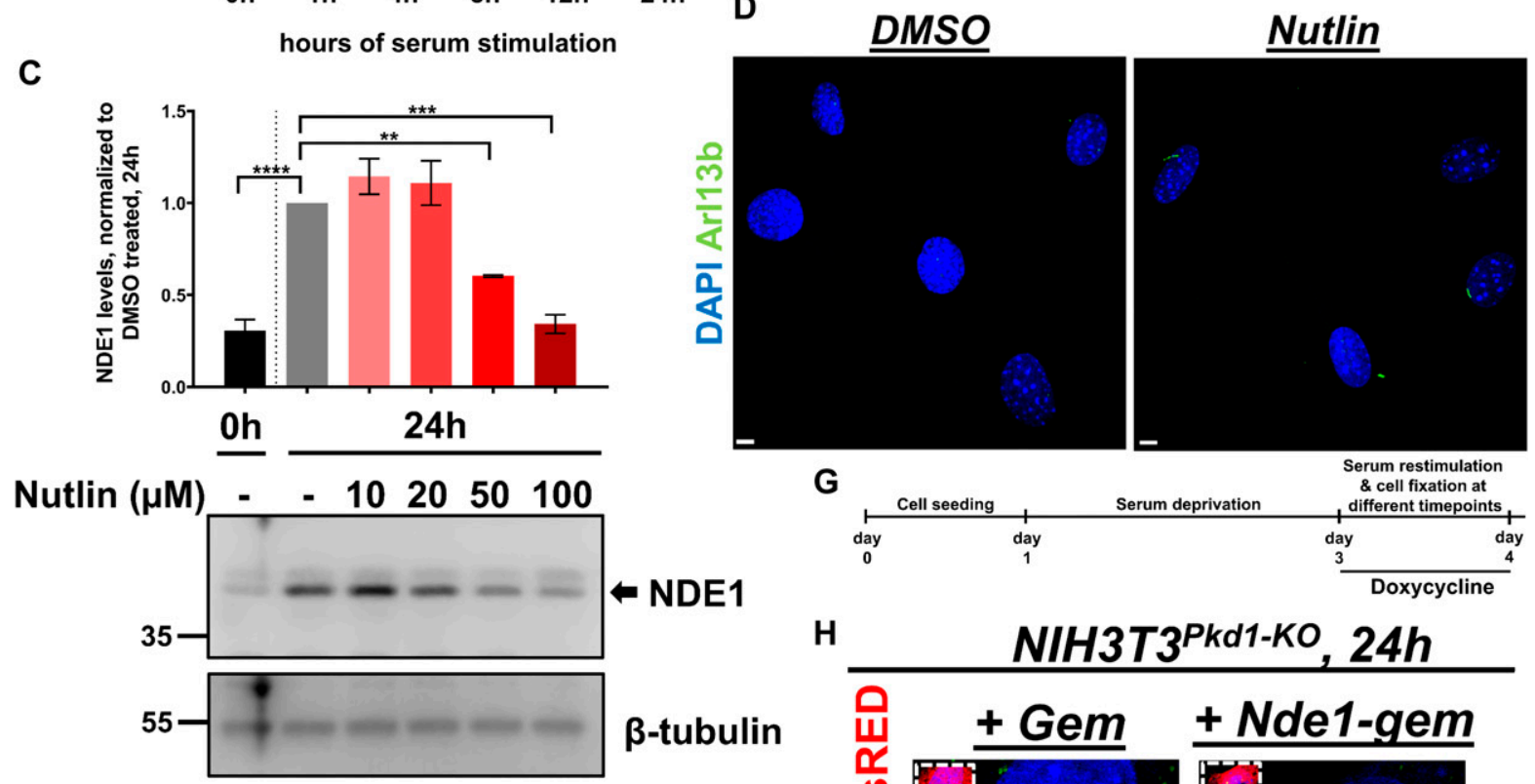

$\beta$-tubulin

E

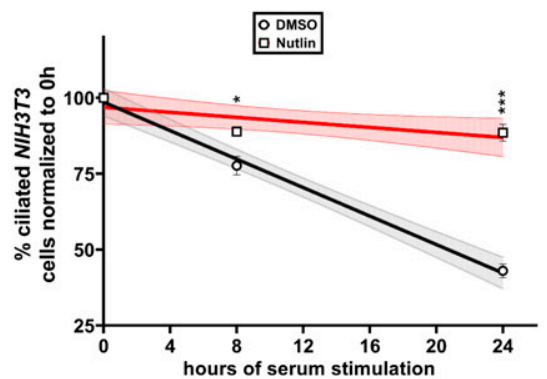

H

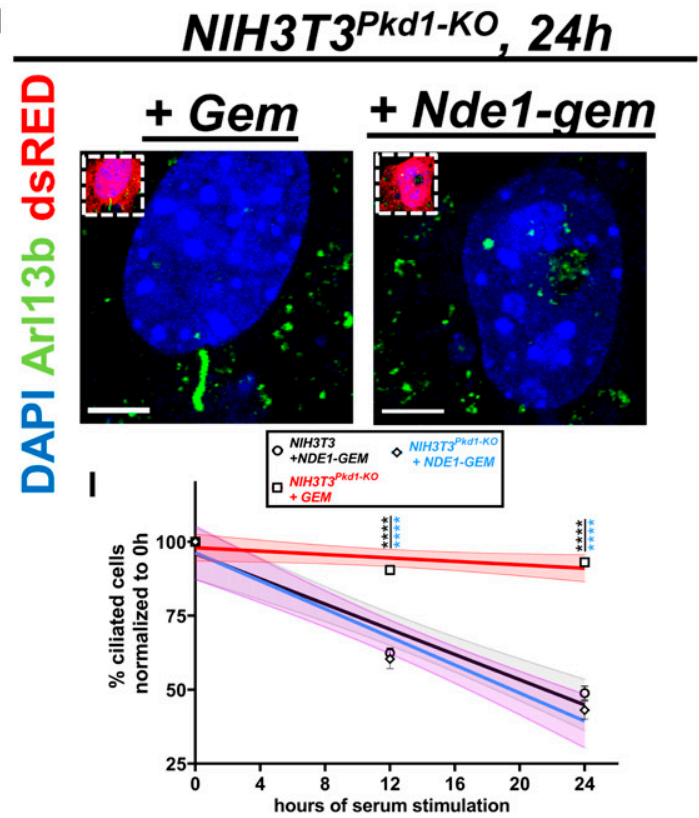

Figure 6. p53 has a negative role in cilia disassembly via down-regulation of NDE1.

(A) Representative time-course of protein levels of various disassembly factors during deciliation in response to serum re-addition in wild-type and Pkd1-null NIH3T3 cells. (B) Summary data of NDE1 protein levels in (A), shown as best-fits with $95 \%$ confidence limits in indicated cell types ( $n=3$ ). Data are presented as means \pm SEM. Twoway ANOVA with Holm-Sidak's multiple comparisons test. ${ }^{*} P<0.05$, ${ }^{* *} \mathrm{P}<0.01$. (C) Bottom: representative protein levels of NDE1 in wild-type NIH3T3 cells at 0 or $24 \mathrm{~h}$ after serum stimulation, after the indicated treatments. Top: summary data of NDE1 levels, normalized to mock treated at $24 \mathrm{~h}$ (gray bar) ( $\mathrm{n}=3$ ). Data are presented as means \pm SEM. One-way ANOVA with Holm-Sidak's multiple comparisons test, ${ }^{* *} P<0.01,{ }^{* \star *} P<0.001,{ }^{* \star * *} P<0.0001$. (D, E) Representative images from wild-type NIH3T3 cells at $24 \mathrm{~h}$ 


\section{Loss of PKD1/PKD2 \\ Centrosomal integrity pathway}

\section{Deciliation rate (gradual disassembly and shedding)}

Persistent ciliary signaling (ie, TGF $\beta /$ Smad)

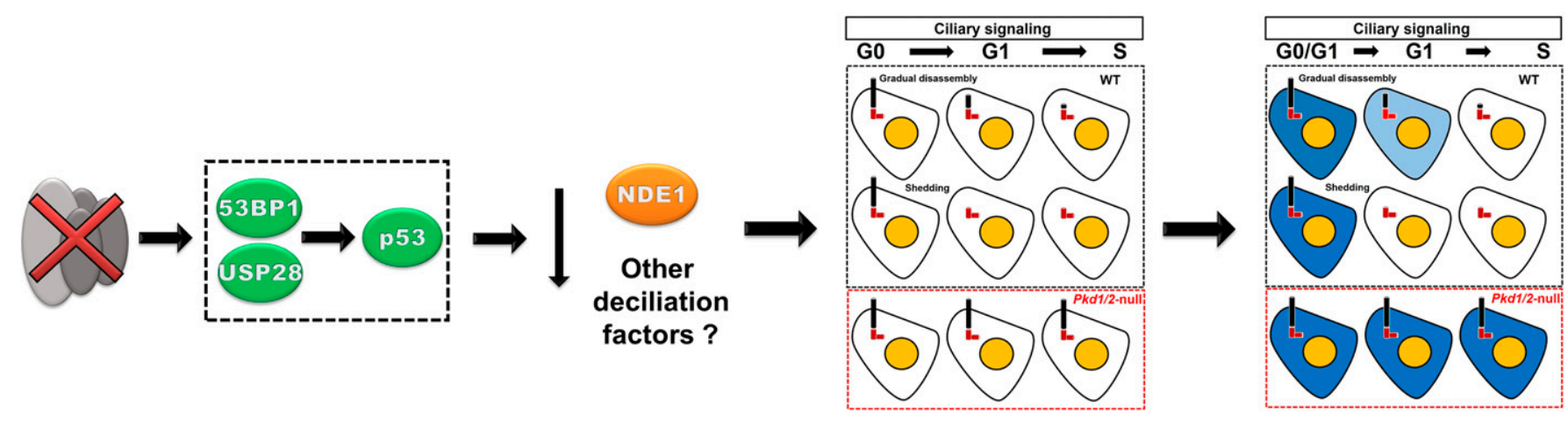

Figure 7. Proposed mechanism by which depletion of PKD1/PKD2 leads to increased cilia-related signaling.

Depletion of PKD1 or PKD2 induces the centrosomal integrity/mitotic surveillance pathway leading to reduced ciliary disassembly and/or shedding (deciliation) rate. Reduced deciliation rate prolongs activation of cilia-dependent signaling pathways (i.e., TGF $\beta /$ Smad, Hedgehog, and Wnt/ $\beta$ catenin).

instability are barely detectable in either wild-type or mutant kidneys. Therefore, we propose that cystic cells progressed to the S phase with partially resorbed cilia or intact cilia. At first, this hypothesis would seem at odds with the increased overall cell proliferation in cystic kidneys. However, there could be several explanations that warrant further consideration. Others and we proposed that accelerated disassembly, or cilia shortening/loss, can speed up cell cycle reentry, whereas delayed disassembly or abnormally long cilia can have the opposite effects (Pan \& Snell, 2007; Kim \& Tsiokas, 2011; Sung \& Li, 2011; Wang \& Dynlacht, 2018). These data have suggested that the primary cilium may function as a physical checkpoint of cell cycle progression. Somewhat counterintuitive to this idea, though, is the fact that primary cilia house numerous signaling pathways, most of which have strong mitogenic effects (Schneider et al, 2005; Christensen et al, 2012; Yeh et al, 2013). In addition, cilia can promote or suppress Hedgehog signalingdependent tumorigenesis depending on the driver mutation (Han et al, 2009; Wong et al, 2009). Finally, cilia confer chemoresistance to certain types of tumors (Jenks et al, 2018). Therefore, it appears that primary cilia can have both positive and negative effects on cell cycle progression. Although they are required for the initiation of mitogenic signaling, they also need to timely disassemble or shed for normal cell cycle progression. Assuming that delayed disassembly does not cause complete cell arrest, it could support persistent cilia-based mitogenic signaling in some number of cells that perhaps stochastically, would not normally enter the cell cycle.
This extra time that cells are exposed to a mitogenic stimulus could lead to more cells eventually entering the cell cycle, increasing the number of proliferating cells. Nevertheless, whether and how delayed deciliation can promote cell cycle reentry in the setting of ADPKD requires further study.

Overall, our studies put forth a new model in which a physiological cellular function of polycystins is to maintain $\mathrm{Cl}$. Loss of this function activates the $\mathrm{Cl} / \mathrm{MS}$ pathway, which in turn signals cells to slow down the rate of deciliation. As a result, cilia-based signaling can persist, promoting cystic growth (Fig 7). The molecular identity of cilia-based signaling pathway(s) with cyst promoting activity is still outstanding, but it could be pathways that mediate mitogenic signaling. Persistent activation of cilia-based mitogenic signaling can recruit kidney epithelial cells in G1/G0 to eventually enter the cell cycle, contributing to cyst expansion and growth.

\section{Materials and Methods}

\section{Cell culture}

$\mathrm{PRd1}^{+/+}$(wild-type) and Pkd1 ${ }^{-/-}$MEFs were obtained from the PKD Baltimore Center. Pkd2 ${ }^{+/+}$and $\mathrm{Pkd2}^{-/-}$mouse inner medullary duct (mIMCD3) cells were a kind gift from the Kleene lab (University of Cincinnati). NIH3T3 cells were obtained from American Type Culture

after serum re-addition, after the indicated treatments. Primary cilia were visualized with Arl13b (green) (D). Serum-induced deciliation rates are shown as best-fits with $95 \%$ confidence limits in indicated treatments $(n=3)(E)$. Scale bars: $5 \mu$ m. Data are presented as means \pm SEM. Two-way ANOVA with Holm-Sidak's multiple comparisons test. ${ }^{*} P<0.05,{ }^{* * *} P<0.001$. $(\mathbf{F}, \mathbf{G}, \mathbf{H}, \mathbf{I})$ Graphic representation of the constructs encoding FLAG-GEMININ or FLAG-NDE1-GEMININ (F). Expression of the constructs was induced by doxycycline induction at the $0 \mathrm{~h}$ time point (G). Representative images from Pkd1-null NIH3T3 cells at $24 \mathrm{~h}$ after serum re-addition, transfected with the indicated constructs. dsRED ${ }^{+}$cells (red) were evaluated for the presence of primary cilia via Arl13b staining (green) (H). Serum-induced deciliation rates are shown as bestfits with $95 \%$ confidence limits in indicated treatments $(n=3)(I)$. Scale bars: $5 \mu$ m. Data are presented as means \pm SEM. Two-way ANOVA with Holm-Sidak's multiple comparisons test. ${ }^{* * *} P<0.001$.

Source data are available for this figure. 
Collection. MEFs were maintained in DMEM ( $4.5 \mathrm{~g} / \mathrm{l}$ glucose, L-glutamine, and sodium pyruvate) supplemented with $1 \%$ penicillin-streptomycin, $1 \%$ nonessential amino acids and 10\% FBS. mIMCD3 cells were cultured in a 1:1 mixture of DMEM and Ham's F-12, supplemented with $10 \%$ FBS. NIH3T3 cells were maintained in DMEM containing $10 \%$ bovine calf serum.

\section{Reagents}

Paraformaldehyde (Cat. no. J19943-K2), EdU (Cat. no. C10337), Prolonged Diamond DAPI (Cat. no. P36966), Trizol (Cat. no. 15596018), and LTX Reagent (Cat. no. 15338100) were purchased from Thermo Fisher Scientific. Nutlin-3 (Cat. no. 3984) and pifithrin- $\alpha$ hydrobromide (Cat. no. 1267) were purchased from Tocris. 4-hydroxytamoxifen was purchased from Sigma-Aldrich (Cat. no. H6278).

\section{Plasmids}

lentiCRISPRV2-puro was a gift from Brett Stringer (plasmid \# 98290; http://n2t.net/addgene:98290; RRID:Addgene_98290; Addgene). pDZ Flag USP28 was a gift from Martin Eilers (plasmid \# 15665; http:// n2t.net/addgene:15665; RRID:Addgene_15665; Addgene). pX330 p53 was a gift from Tyler Jacks (plasmid \# 59910; http:/ / n2t.net/addgene: 59910; RRID:Addgene_59910; Addgene). pcDNA3 flag p53 was a gift from Thomas Roberts (plasmid \# 10838; http://n2t.net/addgene:10838; RRID:Addgene_10838; Addgene). pcDNA5-FRT/TO-eGFP-53BP1 was a gift from Daniel Durocher (plasmid \# 60813; http://n2t.net/addgene: 60813; RRID:Addgene_60813; Addgene).

\section{CRISPR-CAS9 gene editing}

For the generation of $\mathrm{NIH}_{3} \mathrm{~T}^{\mathrm{PRd1}-\mathrm{KO}}$ and NIH3T3${ }^{\text {Pkd2-KO }}$ Clones, NIH3T3 cells were transfected with a lentiviral vector (lentiCRISPRv2-puro) encoding Cas9, resistance to puromycin, and single guide RNA (sgRNA) sequences specific for Pkd1 (5'-AGGGCCGAGTCTGCGCATCC-3') or Pkd2 (5'-AAGTGCTGAAGTCATCGACC-3'). After transfection, the cells underwent serial dilutions and were plated under puromycin selection $(1 \mu \mathrm{g} / \mathrm{ml})$ for $3 \mathrm{wk}$. After selection, single colonies were isolated and expanded. The resulting clones were evaluated for deletion of the genes of interest by Sanger DNA sequencing and Western blotting.

\section{Immunoprecipitation}

Wild-type or Pkd1-null NIH3T3 cell lysates were incubated with two $\alpha$-PKD1 antibodies (7e12; Santa Cruz and E4; PKD Baltimore Center) overnight to immunoprecipitate PKD1. The antigen-antibody complexes were then incubated with Protein $\mathrm{G}$ Sepharose beads for $3 \mathrm{~h}$ in $4^{\circ} \mathrm{C}$. Immunoprecipitates were analyzed for the presence of PKD1 by Western blot.

\section{Indirect immunofluorescence on cultured cells}

Cells were initially seeded on glass coverslips at a density of $\sim 30,000$ cells/well in 24-well plates. To induce synchronization in G1/G0 and primary cilia formation, cells were partially or completely deprived of serum for $48 \mathrm{~h}$. Specifically, MEFs were cultured with OptiMEM low-serum medium, mIMCD3 cells were cultured with
DMEM/F12 medium containing 0.5\% FBS and NIH3T3 cells were kept under DMEM medium with no serum. For induction of deciliation, the cells were restimulated with their respective full growth media (described above). After serum restimulation, the cells were fixed with $4 \%$ paraformaldehyde in PBS, $\mathrm{pH} 7.5$, at different time points. Visualization of primary cilia was performed as described before (Maskey et al, 2015). Briefly, the fixed cells were permeabilized with $0.15 \%$ Triton X-100 in PBS for 90 s and blocked with 3\% goat serum/ $0.15 \%$ Triton $X-100$ in PBS for $1 \mathrm{~h}$. Then, the fixed cells were incubated overnight at $4^{\circ} \mathrm{C}$ with primary antibodies detecting Arl13b (1:500; Proteintech), $y$-tubulin (1:500; Invitrogen), $y$-H2AX (1:200; Cell Signaling), USP28 (1:100; Proteintech), and 53BP1 (1:1,000; Novus Biologicals). Next, the cells were washed $3 \times$ with PBS and incubated with Alexa Fluor-conjugated secondary antibodies (1:2,000; Invitrogen) for $2 \mathrm{~h}$ at $4^{\circ} \mathrm{C}$ protected from light. The samples were then washed $3 \times$ with PBS and mounted with Diamond DAPI (Thermo Fisher Scientific) to counterstain the nuclei. Images were obtained by an Olympus FV1000 confocal microscope and processed with Image software for measurement of ciliary length.

\section{Rescue and siRNA experiments}

For the deciliation rescue experiments, wild-type or mutant NIH3T3 cells were co-transfected, using LTX (Invitrogen), with a plasmid expressing GFP and one of the following plasmids expressing

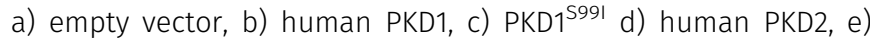
$\mathrm{PKD2}^{\mathrm{D} 511 \mathrm{~V}}$, or f) PKD2 ${ }^{\mathrm{Y} 684 \mathrm{del}}$. Next, the cells underwent synchronization by serum starvation and induced to deciliate and reenter the cell cycle by serum. GFP-positive cells were evaluated for the presence of primary cilia. p53 was targeted using a plasmid expressing single guide RNA targeting mouse p53 (Addgene) in wild-type or mutant NIH3T3 cells. Usp28 and 53bp1 knockdown experiments were performed using SMARTpool: ON-TARGETplus Usp28 siRNA (Dharmacon, Cat. no. L-065548-01-0005) and SMARTpool: ON-TARGETplus 53bp1 siRNA (Dharmacon, Cat. no. L-042290-01-0005), respectively. The cells were co-transfected, using LTX, with GFP and either one of the siRNA constructs and analyzed for the presence of primary cilia after serum-induced deciliation. Expression plasmids bearing USP28, 53BP1, or p53 cDNAs were co-transfected with GFP into wildtype NIH3T3 cells using LTX and GFP-positive cells were evaluated for the presence of primary cilia after serum induction.

\section{Mice and kidney tissue processing}

All procedures were performed according to requirements of the Institutional Animal Care and Use Committee. In this study, three types of C57Bl/6-background mice were used: a) $P k d 1^{f / f}$, as wildtype littermates, b) UbcCre ${ }^{E R T 2} ; P k d 7^{f / f}$, and c) KspCre ${ }^{E R T 2} ; P k d f^{f / f}$. For the deletion of $P k d 1$, nursing dams were intraperitoneally injected with 4-hydroxytamoxifen (4-OHT; Sigma-Aldrich) diluted in corn oil, at $100 \mu \mathrm{g}$ per gram of mouse body weight, from postnatal days 2-6 (P2-P6). $1 \mathrm{~d}$ before euthanasia, the pups were intraperitoneally injected with EdU in PBS ( $20 \mu \mathrm{g}$ of EdU per gram of mouse body weight) and were euthanized after $24 \mathrm{~h}$. Before euthanizing, total body weight of the mice was measured. The kidneys were removed from each mouse and weighed. One of the kidneys was flash-frozen in liquid nitrogen and stored in $-80^{\circ} \mathrm{C}$. Frozen kidneys were later 
lysed and fractionated into nuclear and cytosolic fractions using a Cytoplasmic \& Nuclear Protein Extraction Kit (Cat. no. P504L; 101Bio). The other kidney was split in half, stored in 4\% PFA in PBS overnight, then in $10 \%$ sucrose in PBS overnight, mounted on cryomolds with frozen section compound (Leica) for $30 \mathrm{~min}$ and then flash-frozen on dry ice and stored at $-80^{\circ} \mathrm{C}$. $10-\mu \mathrm{m}$-thick frozen kidney sections were prepared at the University of Oklahoma Health Sciences Center (OUHSC) Stephenson Cancer Center Histology Core and were used for indirect immunofluorescence staining.

\section{Indirect immunofluorescence on kidney tissue samples}

All experiments were performed using the Thermo Scientific Sequenza staining system (Cat. no. 73310017), based on a protocol kindly provided by Dr. Pazour (UMass, MA). Briefly, frozen kidney sections were initially incubated in a Tris-buffered saline-Tween (TBST) bath for 5 min for the removal of frozen section compound and then mounted on coverplates (Cat. no. 7211017; Thermo Fisher Scientific) and incubated with blocking buffer ( $4 \%$ non-immune goat serum $/ 0.1 \%$ cold water fish skin gelatin $/ 0.1 \%$ Triton $X-100$ in TBST) for $30 \mathrm{~min}$. EdU-positive cells were then visualized according to the manufacturer's instructions. If kidney segment staining was desired, endogenous biotin was blocked with a Streptavidin/Biotin Blocking Kit (Vector). After washing $3 \times$ with TBST, endogenous mouse IgG was blocked with Fab antimouse IgG prepared from secondary antibody host for $2 \mathrm{~h}$ (1:10 dilution in $0.1 \%$ fish skin gelatin in TBST; Jackson Immunoresearch). Then, the sections were incubated with primary antibody against acetylated- $\alpha$-tubulin (611b, 1:5,000; Sigma-Aldrich), $y-\mathrm{H} 2 \mathrm{AX}$ (1:200; Cell Signaling) or GEMININ (1:100; Proteintech) overnight at $4^{\circ} \mathrm{C}$ (diluted in $0.1 \%$ fish skin gelatin in TBST). For visualization of kidney segments, the samples were incubated with biotinylated Dolichos Biflorus Agglutinin (Vector) to mark collecting ducts or biotinylated Lotus Tetragonolobus Lectin (Vector) to mark proximal tubules. After $5 \times$ washing in TBST, the sections were incubated with Alexa Fluorconjugated secondary antibodies $(1: 1,000)$ for $1 \mathrm{~h}$ in RT protected from light, washed $5 \times$ with TBST, incubated in a TBST bath for $15 \mathrm{~min}$ and then in a TBS bath for 15 min. Finally, sections were mounted with Diamond DAPI and visualized with confocal microscopy.

\section{Immunoblotting}

Cell lysates were obtained in a lysis solution containing 1\% Triton $\mathrm{X}-100,150 \mathrm{mM} \mathrm{NaCl}, 10 \mathrm{mM}$ Tris- $\mathrm{HCl}$ at pH 7.5, 1 mM EGTA, 1 mM EDTA, $10 \%$ sucrose, a protease inhibitor cocktail (Roche Applied Science), and phosphatase inhibitors $0.2 \mathrm{mM} \mathrm{Na}_{3} \mathrm{VO}_{4}$ and $1 \mathrm{mM} \mathrm{NaF}$ at $4^{\circ} \mathrm{C}$ for $30 \mathrm{~min}$. Cell or tissue lysates were separated with SDS-PAGE. Antibodies were used against p-Smad2 465/467 (1:1,000; Cell Signaling), GAPDH (1:4,000; Genetex), p53 (1:1,000; Cell Signaling or 1:500; Millipore), Dishevelled-2 (1:1,000; Cell Signaling), INPP5E (1:1,000; Proteintech), NDE1 (1:1,000; Proteintech), USP28 (1:1,000; Proteintech), 53BP1 (1:1,000; Novus Biologicals), $\beta$-tubulin (1:1,000; Santa Cruz), $\beta$-actin (1:1,000; Santa Cruz) PKD1 (E8, 1:1,000; PKD Baltimore Center), and PKD2 (G-20, 1:1,000; Santa Cruz). Densitometric quantification was performed with the Licor Image Studio software.

\section{Signaling pathway screening}

Activity of 45 different cellular signaling pathways was measured following the manufacturer's instructions (Cat. no. CCA-901L-12; Qiagen). Briefly, wild-type and Pkd1- or Pkd2-null NIH3T3 cells, or wild-type and Pkd2-null mIMCD3 cells were seeded for reverse transfection in a 96-well plate containing immobilized reporter plasmids. Every pair of wells contained plasmids expressing firefly luciferase in a manner dependent on activity of a specific cellular pathway. Every well also contained a plasmid that constitutively expressed Renilla luciferase, to account for differences in transfection efficiency. Reverse transfection was mediated by Attractene (Cat. no. 301005; Qiagen). Full growth medium was replaced $24 \mathrm{~h}$ after transfection, and cells were lysed in lysis buffer (Cat. no. E194A; Promega) $48 \mathrm{~h}$ after transfection. Cell lysates were incubated with Stop \& Glo substrates (Dual-Luciferase Reporter Assay System, Cat. no. E1960; Promega), and luciferase activity was measured in a Synergy Neo2 Reader (Biotek). All firefly luciferase values were normalized to Renilla luciferase values, and then all mutant sample values were normalized to wild type.

\section{Quantitative RT-PCR (qRT-PCR)}

RNA was extracted and purified from wild-type or Pkd1-null NIH3T3 cells at different time points after serum restimulation using TRIzol reagent (Thermo Fisher Scientific). RNA was reverse-transcribed to CDNA, and samples were amplified by qPCR. mRNA levels of the genes of interest were normalized to wild type at $0 \mathrm{~h}$, via the $\Delta \Delta \mathrm{Ct}$ method. Primers used for qPCR were Usp28 Fw: 5'-AGTTGGGCTGAAAAATGTTGGC-3', Usp28 Rv: 5'-TCAAGGATGTTCTGTGGCAGG-3', 53bp1 FW: 5'-CACGCCAGTTाTCACTCCTG-3', 53bp1 Rv: 5'-TGATGGTTCTTCCAGAC TTGGT-3', Tbp Fw: 5'-TCTACCGTGAATCTTGGCTGT-3', and Tbp RV: 5'GTCCGTGGCTCTCTTATTCTCA-3'.

\section{Statistics}

Software GraphPad Prism 8.3 was used for all statistical analyses described in the text. Quantitative results that required comparisons between groups were subjected to statistical analysis using $t$ test for two groups or one- or two-way ANOVA followed by an appropriate ad hoc test.

\section{Supplementary Information}

Supplementary Information is available at https://doi.org/10.26508/lsa. 202000750

\section{Acknowledgements}

We thank Drs. S Kleene for providing the IMCD3 cells lacking PKD2, G Pazour and $M$ Hinsdale for providing tissue immunofluorescence labeling protocols, and W Berry for advice on CRISPR/Cas9 experiments. We thank the Histology and Immunohistochemistry Core of the University of Oklahoma Health Sciences Center (OUHSC) Stephenson Cancer Center for histology and tissue sectioning, supported by P30CA225520 and P20GM103639. This work was 
supported by DK59599 and DK117654 (National Institutes of Health) and the Presbyterian Health Foundation and the John S. Gammill Endowed Chair in Polycystic Kidney Disease (University of Oklahoma Health Sciences Center) to L Tsiokas. V Gerakopoulos was supported by a predoctoral fellowship from the American Society of Nephrology.

\section{Author Contributions}

V Gerakopoulos: conceptualization, data curation, formal analysis, funding acquisition, investigation, and writing-original draft, review, and editing.

P Ngo: methodology.

L Tsiokas: conceptualization, data curation, supervision, funding acquisition, investigation, project administration, and writingoriginal draft, review, and editing.

\section{Conflict of Interest Statement}

The authors declare that they have no conflict of interest.

\section{References}

Battini L, Macip S, Fedorova E, Dikman S, Somlo S, Montagna C, Gusella GL (2008) Loss of polycystin-1 causes centrosome amplification and genomic instability. Hum Mol Genet 17: 2819-2833. doi:10.1093/hmg/ ddn180

Benzakour O, Merzak A, Dooghe Y, Pironin M, Lawrence D, Vigier P (1992) Transforming growth factor beta stimulates mitogenically mouse $\mathrm{NIH} 3 \mathrm{~T} 3$ fibroblasts and those cells transformed by the EJ-H ras oncogene. Growth Factors 6: 265-275. doi:10.3109/08977199209026933

Bhunia AK, Piontek K, Boletta A, Liu L, Qian F, Xu PN, Germino FJ, Germino GG (2002) PKD1 induces p21(waf1) and regulation of the cell cycle via direct activation of the JAK-STAT signaling pathway in a process requiring PKD2. Cell 109: 157-168. doi:10.1016/s0092-8674(02)00716-x

Bielas SL, Silhavy JL, Brancati F, Kisseleva MV, Al-Gazali L, Sztriha L, Bayoumi RA, Zaki MS, Abdel-Aleem A, Rosti RO, et al (2009) Mutations in INPP5E, encoding inositol polyphosphate-5-phosphatase E, link phosphatidyl inositol signaling to the ciliopathies. Nat Genet 41: 1032-1036. doi:10.1038/ng.423

Breslow DK, Holland AJ (2019) Mechanism and regulation of centriole and cilium biogenesis. Annu Rev Biochem 88: 691-724. doi:10.1146/ annurev-biochem-013118-111153

Burtey S, Riera M, Ribe E, Pennenkamp P, Rance R, Luciani J, Dworniczak B, Mattei MG, Fontes M (2008) Centrosome overduplication and mitotic instability in PKD2 transgenic lines. Cell Biol Int 32: 1193-1198. doi:10.1016/j.cellbi.2008.07.021

Chaki M, Airik R, Ghosh AK, Giles RH, Chen R, Slaats GG, Wang H, Hurd TW, Zhou W, Cluckey A, et al (2012) Exome capture reveals ZNF423 and CEP164 mutations, linking renal ciliopathies to DNA damage response signaling. Cell 150: 533-548. doi:10.1016/j.cell.2012.06.028

Christensen ST, Clement CA, Satir P, Pedersen LB (2012) Primary cilia and coordination of receptor tyrosine kinase (RTK) signalling. J Pathol 226: 172-184. doi:10.1002/path.3004

Clement CA, Ajbro KD, Koefoed K, Vestergaard ML, Veland IR, Henriques de Jesus MP, Pedersen LB, Benmerah A, Andersen CY, Larsen LA, et al (2013) TGF-beta signaling is associated with endocytosis at the pocket region of the primary cilium. Cell Rep 3: 1806-1814. doi:10.1016/ j.celrep.2013.05.020

Davenport JR, Watts AJ, Roper VC, Croyle MJ, van Groen T, Wyss JM, Nagy TR, Kesterson RA, Yoder BK (2007) Disruption of intraflagellar transport in adult mice leads to obesity and slow-onset cystic kidney disease. Curr Biol 17: 1586-1594. doi:10.1016/j.cub.2007.08.034

Fong CS, Mazo G, Das T, Goodman J, Kim M, O'Rourke BP, Izquierdo D, Tsou MF (2016) 53BP1 and USP28 mediate p53-dependent cell cycle arrest in response to centrosome loss and prolonged mitosis. Elife 5: e16270. doi:10.7554/elife.16270

Gabriel E, Wason A, Ramani A, Gooi LM, Keller P, Pozniakovsky A, Poser I, Noack F, Telugu NS, Calegari F, et al (2016) CPAP promotes timely cilium disassembly to maintain neural progenitor pool. EMBO J 35: 803-819. doi:10.15252/embj.201593679

Haimo LT, Rosenbaum JL (1981) Cilia, flagella, and microtubules. J Cell Biol 91 125s-130s. doi:10.1083/jcb.91.3.125s

Han YG, Kim HJ, Dlugosz AA, Ellison DW, Gilbertson RJ, Alvarez-Buylla A (2009) Dual and opposing roles of primary cilia in medulloblastoma development. Nat Med 15: 1062-1065. doi:10.1038/nm.2020

Hassane S, Leonhard WN, van der Wal A, Hawinkels LJ, Lantinga-van Leeuwen IS, ten Dijke P, Breuning MH, de Heer E, Peters DJ (2010) Elevated TGFbeta-Smad signalling in experimental Pkd1 models and human patients with polycystic kidney disease. J Pathol 222: 21-31. doi:10.1002/path.2734

Hopp K, Ward CJ, Hommerding CJ, Nasr SH, Tuan HF, Gainullin VG, Rossetti S, Torres VE, Harris PC (2012) Functional polycystin-1 dosage governs autosomal dominant polycystic kidney disease severity. J Clin Invest 122: 4257-4273. doi:10.1172/jci64313

Ishikawa H, Marshall WF (2011) Ciliogenesis: Building the cell's antenna. Nat Rev Mol Cell Biol 12: 222-234. doi:10.1038/nrm3085

Jenks AD, Vyse S, Wong JP, Kostaras E, Keller D, Burgoyne T, Shoemark A, Tsalikis A, de la Roche M, Michaelis M, et al (2018) Primary cilia mediate diverse kinase inhibitor resistance mechanisms in cancer. Cell Rep 23: 3042-3055. doi:10.1016/j.celrep.2018.05.016

Johnson CA, Collis SJ (2016) Ciliogenesis and the DNA damage response: A stressful relationship. Cilia 5: 19. doi:10.1186/s13630-016-0040-6

Kim H, Bae Y, Jeong W, Ahn C, Kang S (2004) Depletion of PKD1 by an antisense oligodeoxynucleotide induces premature G1/S-phase transition. Eur J Hum Genet 12: 433-440. doi:10.1038/sj.ejhg.5201136

Kim S, Lee K, Choi JH, Ringstad N, Dynlacht BD (2015) Nek2 activation of Kif24 ensures cilium disassembly during the cell cycle. Nat Commun 6: 8087. doi:10.1038/ncomms9087

Kim S, Nie H, Nesin V, Tran U, Outeda P, Bai CX, Keeling J, Maskey D, Watnick T, Wessely O, et al (2016) The polycystin complex mediates Wnt/Ca(2+) signalling. Nat Cell Biol 18: 752-764. doi:10.1038/ncb3363

Kim S, Tsiokas L (2011) Cilia and cell cycle re-entry: More than a coincidence. Cell Cycle 10: 2683-2690. doi:10.4161/cc.10.16.17009

Kim S, Zaghloul NA, Bubenshchikova E, Oh EC, Rankin S, Katsanis N, Obara T, Tsiokas L (2011) Nde1-mediated suppression of ciliogenesis affects cell cycle re-entry. Nat Cell Biol 13: 351-360. doi:10.1038/ncb2183

Kleene SJ, Kleene NK (2016) The native TRPP2-dependent channel of murine renal primary cilia. Am J Physiol Renal Physiol 312: F96-F108. doi:10.1152/ajprenal.00272.2016

Kobayashi T, Dynlacht BD (2011) Regulating the transition from centriole to basal body. J Cell Biol 193: 435-444. doi:10.1083/jcb.201101005

Koulen P, Cai Y, Geng L, Maeda Y, Nishimura S, Witzgall R, Ehrlich BE, Somlo S (2002) Polycystin-2 is an intracellular calcium release channel. Nat Cell Biol 4: 191-197. doi:10.1038/ncb754

Lambrus BG, Daggubati V, Uetake Y, Scott PM, Clutario KM, Sluder G, Holland AJ (2016) A USP28-53BP1-p53-p21 signaling axis arrests growth after centrosome loss or prolonged mitosis. J Cell Biol 214: 143-153. doi:10.1083/jcb.201604054

Lambrus BG, Holland AJ (2017) A new mode of mitotic surveillance. Trends Cell Biol 27: 314-321. doi:10.1016/j.tcb.2017.01.004 
Lee KH, Johmura Y, Yu LR, Park JE, Gao Y, Bang JK, Zhou M, Veenstra TD, Yeon Kim B, Lee KS (2012) Identification of a novel Wnt5a-CK1varepsilonDvl2-Plk1-mediated primary cilia disassembly pathway. EMBO J 31: 3104-3117. doi:10.1038/emboj.2012.144

Leonhard WN, Kunnen SJ, Plugge AJ, Pasternack A, Jianu SB, Veraar K, El Bouazzaoui F, Hoogaars WM, Ten Dijke P, Breuning MH, et al (2016) Inhibition of activin signaling slows progression of polycystic kidney disease. J Am Soc Nephrol 27: 3589-3599. doi:10.1681/asn.2015030287

Li A, Saito M, Chuang JZ, Tseng YY, Dedesma C, Tomizawa K, Kaitsuka T, Sung CH (2011) Ciliary transition zone activation of phosphorylated Tctex-1 controls ciliary resorption, S-phase entry and fate of neural progenitors. Nat Cell Biol 13: 402-411. doi:10.1038/ncb2218

Li X, Luo Y, Starremans PG, McNamara CA, Pei Y, Zhou J (2005) Polycystin-1 and polycystin-2 regulate the cell cycle through the helix-loop-helix inhibitor Id2. Nat Cell Biol 7: 1102-1112. doi:10.1038/ncb1326

Liu H, Kiseleva AA, Golemis EA (2018) Ciliary signalling in cancer. Nat Rev Cancer 18: 511-524. doi:10.1038/s41568-018-0023-6

Low SH, Vasanth S, Larson CH, Mukherjee S, Sharma N, Kinter MT, Kane ME, Obara T, Weimbs T (2006) Polycystin-1, STAT6, and P100 function in a pathway that transduces ciliary mechanosensation and is activated in polycystic kidney disease. Dev Cell 10: 57-69. doi:10.1016/ j.devcel.2005.12.005

Ma M, Tian X, Igarashi P, Pazour GJ, Somlo S (2013) Loss of cilia suppresses cyst growth in genetic models of autosomal dominant polycystic kidney disease. Nat Genet 45: 1004-1012. doi:10.1038/ng.2715

Maskey D, Marlin MC, Kim S, Kim S, Ong EC, Li G, Tsiokas L (2015) Cell cycledependent ubiquitylation and destruction of NDE1 by CDK5-FBW7 regulates ciliary length. EMBO / 34: 2424-2440. doi:10.15252/ embj.201490831

McGarry TJ, Kirschner MW (1998) Geminin, an inhibitor of DNA replication, is degraded during mitosis. Cell 93: 1043-1053. doi:10.1016/s00928674(00)81209-x

Meitinger F, Anzola JV, Kaulich M, Richardson A, Stender JD, Benner C, Glass CK, Dowdy SF, Desai A, Shiau AK, et al (2016) 53BP1 and USP28 mediate p53 activation and G1 arrest after centrosome loss or extended mitotic duration. J Cell Biol 214: 155-166. doi:10.1083/jcb.201604081

Mirvis M, Siemers KA, Nelson WJ, Stearns TP (2019) Primary cilium loss in mammalian cells occurs predominantly by whole-cilium shedding. PLOS Biol 17: e3000381. doi:10.1371/journal.pbio.3000381

Mirvis M, Stearns T, James Nelson W (2018) Cilium structure, assembly, and disassembly regulated by the cytoskeleton. Biochem J 475: 2329-2353. doi:10.1042/bcj20170453

Miyamoto T, Hosoba K, Ochiai H, Royba E, Izumi H, Sakuma T, Yamamoto T, Dynlacht BD, Matsuura S (2015) The microtubule-depolymerizing activity of a mitotic kinesin protein KIF2A drives primary cilia disassembly coupled with cell proliferation. Cell Rep 10: 664-673. doi:10.1016/j.celrep.2015.01.003

Nauli SM, Alenghat F), Luo Y, Williams E, Vassilev P, Li X, Elia AE, Lu W, Brown EM, Quinn SJ, et al (2003) Polycystins 1 and 2 mediate mechanosensation in the primary cilium of kidney cells. Nat Genet 33: 129-137. doi:10.1038/ng1076

Nigg EA, Stearns T (2011) The centrosome cycle: Centriole biogenesis, duplication and inherent asymmetries. Nat Cell Biol 13: 1154-1160. doi:10.1038/ncb2345

Nikonova AS, Astsaturov I, Serebriiskii IG, Dunbrack RL, Jr, Golemis EA (2013) Aurora A kinase (AURKA) in normal and pathological cell division. Cell Mol Life Sci 70: 661-687. doi:10.1007/s00018-012-1073-7

Nikonova AS, Deneka AY, Kiseleva AA, Korobeynikov V, Gaponova A, Serebriiskii IG, Kopp MC, Hensley HH, Seeger-Nukpezah TN, Somlo S, et al (2018) Ganetespib limits ciliation and cystogenesis in autosomaldominant polycystic kidney disease (ADPKD). FASEB J 32: 2735-2746. doi:10.1096/fj.201700909R
Nikonova AS, Plotnikova OV, Serzhanova V, Efimov A, Bogush I, Cai KQ, Hensley HH, Egleston BL, Klein-Szanto A, Seeger-Nukpezah T, et al (2014) Nedd9 restrains renal cystogenesis in Pkd1-/- mice. Proc Natl Acad Sci U S A 111: 12859-12864. doi:10.1073/pnas.1405362111

Pan J, Snell W (2007) The primary cilium: Keeper of the key to cell division. Cell 129: 1255-1257. doi:10.1016/j.cell.2007.06.018

Pazour G) (2004) Intraflagellar transport and cilia-dependent renal disease: The ciliary hypothesis of polycystic kidney disease. J Am Soc Nephrol 15: 2528-2536. doi:10.1097/01.asn.0000141055.57643.e0

Pazour GJ, Baker SA, Deane JA, Cole DG, Dickert BL, Rosenbaum JL, Witman GB, Besharse JC (2002a) The intraflagellar transport protein, IFT88, is essential for vertebrate photoreceptor assembly and maintenance. J Cell Biol 157: 103-113. doi:10.1083/jcb.200107108

Pazour GJ, Rosenbaum JL (2002) Intraflagellar transport and cilia-dependent diseases. Trends Cell Biol 12: 551-555. doi:10.1016/s0962-8924(02) 02410-8

Pazour GJ, San Agustin JT, Follit JA, Rosenbaum JL, Witman GB (2002b) Polycystin-2 localizes to kidney cilia and the ciliary level is elevated in orpk mice with polycystic kidney disease. Curr Biol 12: R378-R380. doi:10.1016/s0960-9822(02)00877-1

Phua SC, Chiba S, Suzuki M, Su E, Roberson EC, Pusapati GV, Setou M, Rohatgi R, Reiter JF, Ikegami K, et al (2017) Dynamic remodeling of membrane composition drives cell cycle through primary cilia excision. Cell 168: 264-279.e15. doi:10.1016/j.cell.2016.12.032

Piontek K, Menezes LF, Garcia-Gonzalez MA, Huso DL, Germino GG (2007) A critical developmental switch defines the kinetics of kidney cyst formation after loss of Pkd1. Nat Med 13: 1490-1495. doi:10.1038/ nm1675

Plotnikova OV, Nikonova AS, Loskutov YV, Kozyulina PY, Pugacheva EN, Golemis EA (2012) Calmodulin activation of Aurora-A kinase (AURKA) is required during ciliary disassembly and in mitosis. Mol Biol Cell 23: 2658-2670. doi:10.1091/mbc.e11-12-1056

Plotnikova OV, Pugacheva EN, Dunbrack RL, Golemis EA (2010) Rapid calciumdependent activation of Aurora-A kinase. Nat Commun 1: 64. doi:10.1038/ncomms1061

Pugacheva EN, Jablonski SA, Hartman TR, Henske EP, Golemis EA (2007) HEF1dependent Aurora A activation induces disassembly of the primary cilium. Cell 129: 1351-1363. doi:10.1016/j.cell.2007.04.035

Reynolds DM, Hayashi T, Cai Y, Veldhuisen B, Watnick TJ, Lens XM, Mochizuki T, Qian F, Maeda Y, Li L, et al (1999) Aberrant splicing in the PKD2 gene as a cause of polycystic kidney disease. J Am Soc Nephrol 10: 2342-2351.

Sanchez I, Dynlacht BD (2016) Cilium assembly and disassembly. Nat Cell Biol 18: 711-717. doi:10.1038/ncb3370

Schneider L, Clement CA, Teilmann SC, Pazour GJ, Hoffmann EK, Satir P, Christensen ST (2005) PDGFRalphaalpha signaling is regulated through the primary cilium in fibroblasts. Curr Biol 15: 1861-1866. doi:10.1016/j.cub.2005.09.012

Shao X, Somlo S, Igarashi P (2002) Epithelial-specific Cre/lox recombination in the developing kidney and genitourinary tract. J Am Soc Nephrol 13: 1837-1846. doi:10.1097/01.asn.0000016444.90348.50

Shibazaki S, Yu Z, Nishio S, Tian X, Thomson RB, Mitobe M, Louvi A, Velazquez $H$, Ishibe S, Cantley LG, et al (2008) Cyst formation and activation of the extracellular regulated kinase pathway after kidney specific inactivation of Pkd1. Hum Mol Genet 17: 1505-1516. doi:10.1093/hmg/ ddn039

Shnitsar I, Bashkurov M, Masson GR, Ogunjimi AA, Mosessian S, Cabeza EA, Hirsch CL, Trcka D, Gish G, Jiao J, et al (2015) PTEN regulates cilia through dishevelled. Nat Commun 6: 8388. doi:10.1038/ncomms9388

Sung CH, Leroux MR (2013) The roles of evolutionarily conserved functional modules in cilia-related trafficking. Nat Cell Biol 15: 1387-1397. doi:10.1038/ncb2888 
Sung CH, Li A (2011) Ciliary resorption modulates G1 length and cell cycle progression. Cell Cycle 10: 2825-2826. doi:10.4161/cc.10.17.16943

Walz G (2017) Role of primary cilia in non-dividing and post-mitotic cells. Cell Tissue Res 369: 11-25. doi:10.1007/s00441-017-2599-7

Wang L, Dynlacht BD (2018) The regulation of cilium assembly and disassembly in development and disease. Development 145 : dev151407. doi:10.1242/dev.151407

Wong SY, Seol AD, So PL, Ermilov AN, Bichakjian CK, Epstein EH, Jr, Dlugosz AA, Reiter JF (2009) Primary cilia can both mediate and suppress hedgehog pathway-dependent tumorigenesis. Nat Med 15: 1055-1061. doi:10.1038/nm.2011

Wong YL, Anzola JV, Davis RL, Yoon M, Motamedi A, Kroll A, Seo CP, Hsia JE, Kim SK, Mitchell JW, et al (2015) Cell biology. Reversible centriole depletion with an inhibitor of Polo-like kinase 4. Science 348: 1155-1160. doi:10.1126/science.aaa5111

Xia S, Li X, Johnson T, Seidel C, Wallace DP, Li R (2010) Polycystin-dependent fluid flow sensing targets histone deacetylase 5 to prevent the development of renal cysts. Development 137: 1075-1084. doi:10.1242/ dev.049437

Xu J, Li H, Wang B, Xu Y, Yang J, Zhang X, Harten SK, Shukla D, Maxwell PH, Pei D, et al (2010) VHL inactivation induces HEF1 and Aurora kinase A. J Am Soc Nephrol 21: 2041-2046. doi:10.1681/asn.2010040345
Yeh C, Li A, Chuang IZ, Saito M, Caceres A, Sung CH (2013) IGF-1 activates a cilium-localized noncanonical Gbetagamma signaling pathway that regulates cell-cycle progression. Dev Cell 26: 358-368. doi:10.1016/ j.devcel.2013.07.014

Yoder BK, Hou X, Guay-Woodford LM (2002) The polycystic kidney disease proteins, polycystin-1, polycystin-2, polaris, and cystin, are colocalized in renal cilia. J Am Soc Nephrol 13: 2508-2516. doi:10.1097/ 01.asn.0000029587.47950.25

Zheng W, Cai R, Hofmann L, Nesin V, Hu Q, Long W, Fatehi M, Liu X, Hussein $S$, Kong T, et al (2018) Direct binding between pre-S1 and TRP-like domains in TRPP channels mediates gating and functional regulation by PIP2. Cell Rep 22: 1560-1573. doi:10.1016/ j.celrep.2018.01.042

Zhou J (2009) Polycystins and primary cilia: Primers for cell cycle progression. Annu Rev Physiol 71: 83-113. doi:10.1146/ annurev.physiol.70.113006.100621

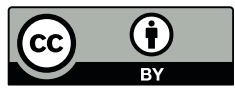

License: This article is available under a Creative Commons License (Attribution 4.0 International, as described at https://creativecommons.org/ licenses/by/4.0/). 